NBSIR 78-1525

\title{
Climate Data Abbreviation for the Computerized Calculation of Heating and Cooling Requirements in Buildings
}

Edward A. Arens

Daniel H. Nall $U / S$ OCLC

Environmental Design Research Division

Center for Building Technology

National Engineering Laboratory

National Bureau of Standards

Washington, D.C. 20234

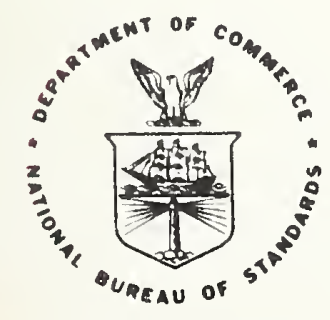

U.S. DEPARTMENT OF COMMERCE 

NBSIR 78-1525

जU

CLIMATE DATA ABBREVIATION FOR

THE COMPUTERIZED CALCULATION

OF HEATING AND COOLING

REQUIREMENTS IN BUILDINGS

Edward A. Arens

Daniel H. Nall

Environmental Design Research Division

Center for Building Technology

National Engineering Laboratory

National Bureau of Standards

Washington, D.C. 20234

December 1978

U.S. DEPARTMENT OF COMMERCE, Juanita M. Kreps, Secretary

Dr. Sidney Harman, Under Secretary

Jordan J. Baruch, Assistant Secretary for Science and Technology

NATIONAL BUREAU OF STANDARDS, Ernest Ambler, Director 


\section{FOREWORD}

This is one of a series of reports documenting NBS research efforts in developing energy and cost data and performance criteria for energy-efficient buildings. The work described in this report was supported by the Department of Energy under the Building Energy Conservation Criteria Program, Task Order A008-BCS to Interagency Agreement No. EA-77-A-01-6010. 


\section{Abstract}

This paper documents the development of a climate data abbreviation technique for building thermal analysis. The paper first discusses the characteristics of computerized building thermal simulations and the requirements of abbreviated data. The technique is then described together with the statistical analyses used to develop it. A series of tests of the representativeness of the abbreviated climate data are documented. Finally, the limitations and potentials of the abbreviation technique are discussed.

Key words: Climate data; computer; energy; load-calculation; residential; weather 


\section{ACKNOWLEDGEMENTS}

We thank William Carroll and Charles Robinson, Thermal Engineering Program, NBS James Filliben, Statistical Engineering Division, NBS, and Julie Pitts, Architectural Research Program, NBS, for their help in preparing and analysing the data presented here. 
I. Introduction . . . . . . . . . . . . . 1

2. Computer Simulations . . . . . . . . . . . 2

3. Abbreviated Climate Data ........... . 4

4. The Abbreviation Methodology . . . . . . . . 6

5. Implementation of the Algorithm . . . . . . . 16

6. Analysis of Results . . . . . . . . . . . 17

7. Conclusion ................. . . 21

Appendix: Listing of Program to Select and Create

Abbreviated Weather Years . . . . . . . . 51 


\section{INTRODUCTION}

Building designers are now commonly analyzing building energy usage with computer programs that calculate the building's thermal response for each hour of a complete year. The results of these computations are used to evaluate alternative building design and mechanical equipment schemes, to establish compliance with codes, and to predict operating costs.

In addition to a complete description of the building, these programs require a continuous year of hourly observations of weather conditions for the building's location. Magnetic tapes with one year of recorded weather values for various locations are made available by the National Climatic Center of the National Oceanic and Atmospheric Administration. Data recorded on these tapes include dry and wet-bulb temperatures, cloud cover and type, wind speed and direction, barometric pressure and precipitation. Using each hourly set of these variables in turn, the hour-by-hour program calculates the heat fluxes in the building. Thus, in order to calculate the energy requirements for the annual cycle, the program must perform 8760 separate sets of calculations. As a result, the program of ten consumes large amounts of computer time and is relatively costly.

This paper describes a technique for reducing the time required for a yearly analysis by selecting a smaller sample of hours to represent the entire year。 The technique is termed a climate data abbreviation and is incorporated into a computer program which automatically reads the full year weather file and creates a short verion. The characteristics of the hour-by-hour building thermal simulation are presented first to demonstrate its value as an analysis tool and its costs in computer time. Then the benefits and limitations of climate data abbreviation for reducing computer time requirements are discussed. The 
paper describes the development of the technique through statistical analyses, and gives the results of various tests of its performance. Finally, suggested improvements and future work are discussed.

\section{COMPUTER S IMULATIONS}

The hour-by-hour computer simulation is currently acknowledged as the most accurate method of calculating heating and cooling requirements for buildings. [1] A number of hourly simulation programs are available to researchers and practitioners either as software packages or througin time-sharing organizations. Some of the more widely used programs include:

$\begin{array}{ll}* \text { Calcon-DoE } 1 & \text { University of California, Berkeley } \\ \text { TRACE } & \text { The Trane Company } \\ \text { AXCESS } & \text { Edison Electric Institute } \\ \text { E-Cube } 75 & \text { American Gas Association } \\ \text { HCC III } & \text { Automated Procedures for Engineering Consultants } \\ \text { NBSLD } & \text { The National Bureau of Standards } \\ \text { NECAP } & \text { National Aeronautics and Space Administration } \\ \text { BLAST } & \text { U.S. Army Construction Engineering Research } \\ & \text { Laboratory }\end{array}$

These programs have been widely used in the recent past and users have made substantial investments for both acquisition costs and training costs. Any technique for reducing the computational requirements in predicting the energy needs of a building should recognize the widespread distribution of the currently available programs.

* was Cal-Erda before 1978 
Most of these programs share algorithms that were developed under the guidance of the ASHRAE Task Group on Energy Requirements and which have been published by ASHRAE. [2] The algorithms permit the accurate modeling of the thermal interactions among the various components of the building. The primary rationale for the hour-by-hour simulation is that heat transfer phenomena in a building are time dependent processes for which one hour is a reasonable computational time step. Integration in steps smaller than the one hour period results in little gain in accuracy except in some specific research applications. [3] Lengthening the time step for the calculation would drastically affect the ability of the program to quantify two of the most important energy conserving phenomena, storage of heat over the diurnal period, and the correspondence of the occupancy, lighting and temperature control schedules with the daylight hours. The phenomena considered in most of these program includes not only the conductive heat flux through the envelope elements, but also air leakage, solar heat gain through translucent elements, solar gain on opaque surfaces, heat storage effects, internal heat load and wind forced convection. Because of the thermal interaction of the building elements; a change in one element for conservation purposes may alter the effects of these phenomena on the other elements of the building. Reducing the complexity of the computer simulation may result in a lack of sensitivity in the program for comparing similar conservation strategies.

An unfortunate by-product of the complexity of the calculations in a building thermal analysis program is the amount of computer time required and the resultant cost of performing an analysis. In an ideal process of designing a building, analyses would be performed to evaluate the thermal consequences of each major design decision. By knowing the thermal performance of each energy conserving option on a specific building, the designer may select the most effective set 
for that building. For example, during the predesign phase of the GSA Norris Cotton Federal Office Building, in Manchester, N.H., National Bureau of Standards engineers performed scores of simulation analyses to determine the ideal aspect ratio, percentage of glass on each face, thermostat strategy, and insulation placement for energy conservation. [4]

Unfortunately, currently available simulation programs are simply too expensive to use routinely in a formal or even informal optimization process. For time sharing users of these programs much of the high cost of their use is caused by the large amounts of computer time needed to perform the analysis. Time requirements for the analysis can be divided generally into initialization time and calculation time. The calculation time is a linear function of the number of hours to be simulated and accounts for between 90 and $95 \%$ of the total time required. Thus a significant decrease in the computer time requirements can be achieved only by optimizing the algorithms within the computation loop or by decreasing the number of iterations required to characterize an entire year. Any method of achieving this decrease should be easily applicable to most of the computer programs currently available.

\section{ABBREVIATED CLIMATE DATA}

A promising approach to the reduction of computer time and the associated costs of hour-by-hour building thermal simulations is to abbreviate the climate data tapes supplied by NOAA. In this approach, a sample of hourly sets of data represents the 8760 hours of data on the NOAA tape. The integrated heating and cooling requirements calculated by using this sample are scaled to yearly requirements by the ratio of 8760 hours to the number of hours in the sample. This approach fulfills the two requirements developed in the previous section: 
(1) maintenance of the sensitivity of hourly analyses to time-dependent effects of detailed architectural design options; (2) ability of the method to be used with unmodified versions of the simulation programs currently available。 Reducing the number of hourly repetitions required to characterize the year is not only sino and more universally applicable than optimizing the algorithms within the program but is also a more effective means of reducing the costs of computation. Reducint: the number of days used to characterize the year provides the additional benefit of reducing the amount of output to be analyzed. Results of simulations using a sufficiently abbreviated year may be presented in a simple graphic format, with the characteristic daily profiles of loads and temperatures for each month plotted on a single page.

The abbreviated weather data that represents the full year may either be synthetic data generated from statistical summaries of the year, or may be a set of selected segments from the hourly observations on a weather tape. One advantage cited for synthetic weather data in general has been that a weather tape for a new location may be conveniently generated using data readily available in published statistical summaries [12]. However, certain subtleties of weather that may be very important in determining the suitability of a building design to its location may not be characterized in the available published summaries. The analysis needed to incorporate such subtleties in synthetic data becomes quite complex, and requires input that can only be gained by processing an actual weather tape. Examples of daily subtleties important to building design are consistent morning fogs, sea breezes, and afternoon cumulus cloud development. On a seasonal basis, the correlation of high winds with low temperature during cold front passages increases the effect of the low temperature on energy consumption in buildings. In order to fully characterize a particular climate, the synthesis must be able to capture the diurnal temperature range and distribution, 
the distribution of cloud cover and wind over the day, and the correlations of wind, humidity, cloud cover, and temperature which are distinctive to the location.

Actual data on the other hand can be assumed to demonstrate, over the course of an appropriately sized sample, some of the subtle characteristics of the local climate. This is particularly true for diurnal distributions of climate variables. A NOAA weather tape in either TD 1440, TRY, or SOLMET format may be used to provide the base data from which the sample is selected. The means for selecting the sample should be designed to insure that the calculated heating and cooling requirements of vàrying building configurations using the sampled data are as close as possible to those of the full year. In addition, the technique should assure that the sample contain both the peculiarities and the extremes of the local climate, because these may have important ramifications on building design in that area.

\section{THE ABBREVIATION METHODOLOGY}

The abbreviation technique developed here uses segments of actual weather data to make up the short year. The time units in which both climate reports and load calculation programs summarize data determine the general format of the abbreviated short year tape. For example, the NBSLD program outputs both a daily and monthly summary in addition to its hourly output file. Long-term climate summaries published by NOAA report monthly averages. Therefore, it is convenient for the short weather tape to represent each month, using a shorter interval of days. The simulation using such a short year provides not only total yearly results but also an indication of monthly results.

Averages for weather variables within the sample may be compared with averages for the month from the full year tape and also with long term averages from 
published sources. If the sample selection methodology uses monthly averages in selecting the sample its user has the opportunity to select a sample representative of long-term average climate from a single or limited number of yearly weather tapes. The input data for the selection process in this case would be taken from the long-term monthly averages published by NOAA. Representation on a monthly basis also presents other advantages. The scale of weather variation within a month is small compared with that of a full year, so that the varying solar geometry throughout the year is well represented by including samples from each month, and the general boundaries of the heating and cooling seasons may be determined.

In this abbreviation technique, the days selected to represent each month are contiguous in order to minimize the discontinuities created when disjunct hours of climatic data are juxtaposed. The only discontinuities created by this abbreviation process are then those between the blocks of days from each month. Thus for each month there are $(m-n+1)$ contiguous intervals, where $m$ is the length of the month and $\mathrm{n}$ is the length of the interval that is used to represent the month. In this research work, an interval length of four days has been used. The program has been written so that the length of the interval is a variable that is input by the user. This interval length of four days. has proven adequate for light weight buildings, and gradually becomes less accurate with increasing building mass.

Several criteria were identified in determining the nature of the algorithm for selecting the appropriate intervals. First, the algorithm should be biased as little as possible toward any particular building type or climate. A short year adhering to this criterion could be created once and reused for many buildings. In addition, the same algorithm could be used to create short years 
for many climates. Second, the statistics used for selection should be based as directly as possible on the effects of climate variables on building energy usage. Third, the selection algorithm should be able to utilize characterizing statistics not only from specialized analysis of a particular year of hourly observations, but also from long-term published averages. These criteria allow the creation of an abbreviated tape representative either of a particular year at a site or of the long-term conditions at that site.

The algorithm developed to meet these criteria bases the selection on the deviation of the interval averages from the monthly averages for the climate variables. A single composite score for the interval is generated by summing the deviations of the variables with each weighted, according to the impact of the variable on energy usage in buildings. Several assumptions underlie this algorithm. The most important of these is that heating and cooling requirements for a month are approximately a linear function of the monthly averages of certain weather statistics. The second assumption is that the importance of each climate variable to heating and cooling requirements is of the same order of magnitude for wide variety of buildings. This assumption can be restated as follows: if the building envelope determined heating and cooling requirements can be represented as a linear function of several climatic variables, then the ratio of any two coefficients for the climate variables will be of the same order of magnitude over a variety of buildings. Given these two assumptions, the coefficients of the linear model become the weights for computing the composite score.

A final consideration in developing this technique was that during temperate months, heating and cooling requirements are a function of excursions from the mean temperature rather than the mean temperature itself. The temperature range 
over the interval, however, is not an appropriate component for a linear model and therefore does not lend itself țo the composite scoring methodology. In order to insure that the interval both conforms to the means and has wide variation, the algorithm selects the interval with the greatest temperature range from among those intervals with composite scores below a set maximum value. The algorithm may be tuned to account for the relative importance of the climatic mean and temperature range by adjusting this maximum score.

In order to implement the climate data abbreviation technique outlined above, one must determine the importance of various climate variables to building energy usage. The measure of this importance would be a set of numerical weights by which the deviations of the climate variables between the interval and the month can be converted to a single score. Variations in geometry, orientation of glazing, internal heat sources, and operating conditions cause each building to respond uniquely to changes in climate variables. To create weights typical of a wide variety of buildings, a testing program was set up to determine the range of responses of different buildings to climate variables in several geographic locations, for both heating and cooling.

Several assumptions, made previous to the design of the testing program, allowed the scope and effort to be limited. The abbreviation technique was assumed to be applicable to moderately well insulated building with skin dominated loads. It was also assumed to be applicable only to locations in the continental United States. Accordingly, three building configurations, a light building, a heavy building, and a solar intensive building, were selected and were simulated using TRY climate tapes in three geographic locations. [5] Calculated heating and cooling requirements were then subjected to least squares regression analysis with climate variables. The range of variation of these normalized coefficients, 
their calculated significance levels, and goodness-of-fit considerations could determine which variables were important and whether a single set of weights were justifiable. Specifically, one could examine the assumptions of linearity and limited variation mentioned under the previous heading.

The three residential building types were selected to maximize the variation in their response to climate variables. The first type is a compact 'ranch style' house representative of today's construction practices. [6] The 1200 square foot $\left(111.5 \mathrm{~m}^{2}\right)$ house has 55 square feet $\left(5.1 \mathrm{~m}^{2}\right)$ of window facing north and 72 square feet $\left(6.7 \mathrm{~m}^{2}\right)$ facing to the south. Figure 1 shows plans, elevations and a section. The walls are insulated to $\mathrm{R}-11\left(1.94 \mathrm{~m}^{2}{ }^{\circ} \mathrm{C} \mathrm{W}^{-1}\right)$ and the attic to $\mathrm{R}-19\left(3.34 \mathrm{~m}^{2}{ }^{\circ} \mathrm{C} \mathrm{W}^{-1}\right)$. Single glazing is used in all windows. The base rate for infiltration is assumed to be $1 / 2$ air change per hour, and varies with the wind and the temperature differences between interior and exterior. The second house is a passive solar variant of the ranch house. The south glazing is increased to 140 square feet $\left(13.0 \mathrm{~m}^{2}\right)$ and is protected by a $4.5 \mathrm{ft}(1.37 \mathrm{~m})$ foot overhang. Wall insulation is raised to $\mathrm{R}-15\left(2.64 \mathrm{~m}^{2}{ }^{\circ} \mathrm{C} \mathrm{W}^{-1}\right)$ and double glazing is used. The four inch $(.10 \mathrm{~m}) \mathrm{slab}$ and carpet are replaced with a six inch $(.15 \mathrm{~m}) \mathrm{slab}$ with tile which is laid over two inches $(.051 \mathrm{~m})$ of polystyrene foam insulation. North facing glazing is reduced to 40 square feet $\left(3.72 \mathrm{~m}^{2}\right)$. Plans and sections of the building are shown in Figure 2. The third building is a massive infill building with party walls oriented north and south. The party walls are constructed of 8 -inch $(.20 \mathrm{~m})$ concrete with dry wall finish. The roof is constructed of precast plank with lightweight concrete insulation. The east and west walls are of brick and block construction with $100\left(23 \mathrm{~m}^{2}\right)$ square feet of glazing in each face (Figure 3). The variations in orientations, mass, insulation level 
and glazing area represent a wide range of construction practice and constitute a good test for variation of response to climate variables. The schedules of internal heat sources in each house was based on occupancy by a family of four. The three climates chosen, Washington, D.C., Phoenix, Arizona and Minneapolis, Minnesota encompass most of the variation found within the continental United States. Washington is a temperate coastal climate which is humid in the summer. Minneapolis is a cold continental climate, while Phoenix is a hot arid continental climate. The climates represent variations, not only in temperature and humidity, but in daily temperature range, wind speed, and cloud cover.

The initial set of simulations were calculated using thermostat settings of $68^{\circ} \mathrm{F}\left(20^{\circ} \mathrm{C}\right)$ for heating and $78^{\circ} \mathrm{F}\left(25.6^{\circ} \mathrm{C}\right)$ for cooling. These settings may be considered prudent standard practice. Each house was simulated in each location using the NBSLD program. [7] Heating and cooling requirements were summed on a daily basis and were subjected to regression analysis using temperature, wind speed, cloud cover and daily range as independent variables. Analysis of the regression results revealed several complications which necessitated a different approach to both the simulation and the regression. A graph of daily heating and cooling requirements against daily mean temperature for the passive variant in Washington, D.C. (Figure 4) reveals the primary complication: the relationship is not linear. The dead zone between $68^{\circ} \mathrm{F}\left(20^{\circ} \mathrm{C}\right)$ and $78^{\circ} \mathrm{F}$ $\left(25.6^{\circ} \mathrm{C}\right)$, in which temperature changes have no impact on heating and cooling requirements, creates a discontinuity. A second complication occurred on days in which both heating and cooling requirements were calculated. The thermal behavior of the buildings on these days could not successfully be represented as a function of daily averages of climate variables. 
According to theory, heat transfer between the interior and exterior of the building is a continuous function of temperature differentials. The discontinuity shown in Figure 4 is caused by the effect of the thermostat settings on the conversion of thermal gain or loss to heating or cooling requirements. The nonlinearities in heating and cooling requirements caused by changeover from heating to cooling or by thermostat deadzone prevent the calculation of a suitable regression model. A thermostat strategy was therefore sought that would result in the most straightforward conversion of thermal gain or loss to heating or cooling requirements. For the second set of simulations, each building in each location was run twice; once with a low thermostat setting resulting in cooling requirements only throughout the entire year, and once with a high setting so that heating requirements only were calculated. The thermostat setting used were $112^{\circ} \mathrm{F}\left(38.9^{\circ} \mathrm{C}\right)$ and $22^{\circ} \mathrm{F}\left(-5.6^{\circ} \mathrm{C}\right)$. The results of using the two thermostat settings can be compared to determine how the behavior of the building differed for heating and cooling. Conversion of heat gain or loss to heating and cooling requirements is almost independent of climate and therefore, coefficients developed for a constant thermostat setting should be valid for selecting climate samples for use with varying thermostat schedules.

Some experimenting was also required to identify suitable climate variables for the selection algorithm. Those variables initially thought to be important were temperature, solar radiation, wind, daily temperature range, and humidity. Solar radiation values are not, however, included in the TRY format tapes. Solar radiation values needed for NBSLD are constructed from the cloud cover values on the tape using the algorithm developed by Liu and Jordan. [8] It was decided, for the following reasons, to use cloud cover as an independent 
variable, rather than reconstructing solar radiation values. Construction of solar radiation values and summation for a day requires integration of the radiation on a specifically oriented surface. By selecting such a surface, one might cause a geometric bias in the independent variable. Cloud cover represents solar radiation on the building without being specific to any geometry. Also, long-term monthly averages for cloud cover are available for most locations, while those for solar radiation are not.

Regressions were run on the daily sums and averages for both the entire year and each month in order to check the linearity of the model. Ideally, the coefficients calculated for each month should be similar to one another and to those calculated for the entire year. The coefficients for temperature exhibited this similarity, while those for cloud cover and wind did not. For some of the buildings, the coefficient for cloud cover exhibited a change of sign from summer to winter. The coefficient for wind speed became negligible during winter for the cooling simulations and during summer for the heating simulations.

Analysis of these results suggested some changes for both dependent and independent variables. The change in sign for the cloud cover coefficient was most dramatic in the cooling simulation of all three buildings in Washington, D.C. The probable cause of this anomaly was the high correlation between cloud cover and relative humidity. The summer coefficients for cloud cover for the Washington, D.C. cooling simulations were correlated to high latent loads. For the ranch and passive houses, which have no east-west windows, the increase in solar load correlated to the reduction in cloud cover was overwhelmed by the decrease in latent load also correlated with the cloud cover reduction. This dilemma could be solved only by splitting the dependent variable, total load, into 
two variables: latent load and sensible load. Note that neither the calculation of solar radiation values from the cloud cover parameter, nor the use of actual radiation values, would have eliminated the correlation between sunlight and humidity that caused the unstable coefficients. The regression therefore was performed using sensible load as the dependent variable, and the change of sign in the cloud cover coefficient was eliminated. Cloud cover coefficients for each month varied across the year. Each building type, however, varied similarly in all three locations indicating that the probable cause was the shifting geometry of the sun to the building.

The change of the wind coefficient suggested that a temperature-wind product might be a more indicative variable. The use of such a product for modeling the thermal performance of buildings had been suggested in the Twin Rivers study at Princeton. [9] The regression with this product was occasionally unstable with mutually cancelling variations between the coefficients calculated for the two variables. Interestingly, the locations themselves demonstrated a specific pattern for this phenomenon over all three houses, indicating that the variations were a function of the particular weather rather than the building. Changing the variable from the product of the average daily temperature and the average daily wind speed to the daily average of the hourly wind-speed temperature product eliminated this problem and permitted a stable coefficient to be obtained.

The climatic variable most indicative of the latent load was discovered in a slightly different way. By observing months in which the interior-exterior temperature difference and the exterior relative humidity result in a direct conversion of latent gain or loss to requirements for humidity adjustment (instead of merely acceptable changes in the interior relative humidity), it was found 
that most of the variation of the calculated latent load is a function of the change in the moisture ratio of the exterior air.

The coefficient for this variable developed by regression ranged between 6480 and $11400\left(\mathrm{Btu} \cdot \mathrm{ft}^{3}\right) /(\mathrm{hr} \cdot \mathrm{lb})\left[427\right.$ and $\left.752\left(\mathrm{~kJ} \cdot \mathrm{m}^{3}\right) / \mathrm{hr} \cdot \mathrm{kg}\right]$. Latent gains or losses by infiltration are calculated directly in the NBSLD program as a function of moisture ratio and infiltration-rate. By using the equation from NBSLD and an infiltration rate of .5 air changes per hour, a coefficient of 9158.4 (604) was calculated for the average volume of the three houses. As this value was near the mean of the coefficients developed by regression, it is used in the selection algorithm. The moisture ratio may be calculated directly from dry-bulb and dew point temperatures using ASHRAE approved algorithms. [2]

Table 1 gives normalized values for the coefficients calculated for sensible loads in each of the houses in each location in both heating and cooling modes. The relative importance of the climate variables is shown not to vary much anong the three building types in all climates. This lack of variation supports the second underlying assumption of the method, so that the abbreviation technique is valid for a wide range of buildings.

The generalized weights for use in the abbreviation technique were taken from the mean value of the annul raw coefficients for each climate variable.

The final equation for the composite score is:

$$
\text { Score }=7.5|\Delta \mathrm{DB}|+4.7|\Delta \mathrm{CC}|+.1|\Delta \mathrm{WSDB}|+9158.4|\Delta \mathrm{WA}|
$$




$$
\begin{aligned}
& \text { where } \triangle \mathrm{DB}=\text { deviation of dry bulb temperature }\left({ }^{\circ} \mathrm{F}\right) \\
& \Delta \mathrm{CC}=\text { deviation of cloud cover (tenth of cover) } \\
& \Delta \mathrm{WSDB}= \\
& \quad\left({ }^{\circ} \mathrm{F} \text { Miles } \mathrm{hr} \cdot{ }^{-1}\right) \\
& \Delta \mathrm{WA}=\text { deviation of wind speed drybulb temperature product }
\end{aligned}
$$

\section{IMPLEMENTATION OF THE ALGORITHM}

A computer program was written incorporating the abbreviation technique outlined previously and the findings of the investigation of climate variables. A listing of the program is given in Appendix A: In creating an abbreviated version of a TRY tape, the program first calculates average values for each month for the following variables: temperature, cloud cover, wind-temperature product, and absolute humidity. The program then calculates the averages of these variables for each contiguous four day interval in the month. The deviations between the averages for the interval and the month are weighted and combined to a single score for each interval with the lowest score being the best. From those intervals in the lowest $15 \%$ of al1 scores, that interval with the largest range of temperatures is selected. This range was arrived at by a process of tuning; comparing the results of the short year and full year simulations for the three buildings in the three locations.

For abbreviation of a TRY tape by correction to long-term averages, monthly longterm averages from NOAA for dry-bulb temperature, cloud cover, wind speed, and dew point temperature are input. Algorithms convert these variables to those given above to allow the user to compare them to the monthly averages found on the tape, and the program proceeds as before, comparing the intervals to long-term monthly averages. 
The short year for use with the NBSLD program consists of twelve intervals that represent the twelve months of the year, plus an initial four days of data for initialization purposes. Because the NBSLD program is a transfer function program, it bases its calculations not only on the conditions for the current hour of calculation but also on a history of conditions. Thus the simulation must be run for a number of iterations to allow the initialization errors to be purged. The initial four day run period, which consists of four repetitions of January 1 from the tape, allow this "warming up" process to occur.

\section{ANALYSIS OF RESULTS}

The first test performed was the verification of daily mean temperature as one of the climate variables, instead of the more precise degree-hour measure. A recent paper demonstrated that the use of the degree-hour resulted in better characterization of climate than daily mean temperature. [10] In order to test the importance of this distinction, a version of the abbreviation program was created that employed degree hours instead of daily mean temperature. The weight used to combine the deviation between the interval and the month for this variable was merely the weight for temperature divided by 24 . The base temperatures used to calculate heating degree-hours was $55^{\circ} \mathrm{F}\left(12.8^{\circ} \mathrm{C}\right)$, and for cooling degreehours, $68^{\circ} \mathrm{F}\left(20^{\circ} \mathrm{C}\right)$. When this program was run for six TRY sites, very little change was noted from the program utilizing daily mean temperature. In fact, for every month tested, the interval obtaining the best composite score using daily mean temperature also obtained the best score using degree-hours. The results of this test indicate that daily mean temperature is an adequate measure for abbreviation purposes. The use of mean temperature has the advantage of allowing modification of the short year to long term means, because long term mean temperatures are published while degree-hours are not. 
The abbreviation technique was applied to six TRY climate tapes for the initial testing. In addition to the sites for which climate variables were tested, Washington, D.C., Minneapolis, Minnesota and Phoenix, Arizona, three additional sites, Miami, Florida; Columbia, Missouri and Boston, Massachusetts were added. These three sites were chosen for their diversity, representing respectively a coastal warm climate, a continental temperate climate, and a coastal cool climate. Full year analyses were run for each of the three building types in each of the six climates, and were compared with respective short year analyses. The results of this comparison can be seen in Figures 5 through 22 .

On the basis of the yearly summations, the correspondence between the short year and full year results is quite good. For heating, the correlation coefficient between the two results for the 18 examples is .9987 and for cooling the coefficient is .9978. The RMS error for heating is $89.4 \times 10^{4} \mathrm{Btu}\left(94.32 \times 10^{7} \mathrm{~J}\right)$ with the mean heating value of $1751.6 \times 10^{4} \mathrm{Btu}\left(110.99 \times 10^{7} \mathrm{~J}\right)$. For cooling the error is $105.2 \times 10^{4} \mathrm{Btu}\left(110.99 \times 10^{7} \mathrm{~J}\right)$ for a mean of $1617 \times 10^{4} \mathrm{Btu}(1708.05$ $\left.\mathrm{x} 10^{7} \mathrm{~J}\right)$. The RMS error for the sum of heating and cooling requirements over the 18 examples is $119.4 \times 10^{4}$ Btu $\left(125.97 \times 10^{7} \mathrm{~J}\right)$.

Closer inspection of the results gives some insight into the usage and limitations of the short years. Both the passive and the townhouses suffer to some extent from errors caused by the drastically increased rate of seasonal change in the short years. A good example is the month of November for the Washington townhouse. Because each month is represented by only four days, the heating of the massive masonry and concrete townhouse during the eight days representing August and September could continue to significantly affect the response of the house as many as eight days later. This house, however, represents as massive a building as might normally be encountered (the roof section has 48 significant transfer 
functions and a common ratio of .9226). The magnitude of this error can be seen by comparing the totals for the interval from the short year analysis to the totals calculated for that four days extracted from the full year analysis. For the example given above, the actual calculated heating requirement for the four days representing November from the short year, before multiplication by 7.5 to represent the entire month, is $2.92 \times 10^{4} \mathrm{Btu}\left(3.08 \times 10^{7} \mathrm{~J}\right)$. The calculated heating requirement for those four days from the full year analysis is $14.03 \times 10^{4}$ Btu $\left(14.80 \times 10^{7} \mathrm{~J}\right)$. The difference between these two calculations is that in the short year the interval is preceded by four days from October, four from September, and so forth. The interval from the full year is preceded by other November days. Despite the magnitude of this error for the month of November, the total error for the yearly summation is $-8.8 \%$.

Another method of looking at the results of this analysis is to examine the ability of the short year to predict the differences in heating and cooling requirements between the three building types. Results of this examination are shown in Table 2.

The figures given are for the sum of heating and cooling requirements for each house in each location. The addition of the heating and cooling requirements is a reasonable representation of the total energy required for conditioning the house assuming fossil fuel heating and electric air conditioning. The short year predictions of savings in the modification of the ranch house to the passive house are uniformly good, with the possible exception of Phoenix, for which the difference between passive and ranch is less than the precision of the short year method as demonstrated by the RMS error for the group. The difference between the ranch and townhouses was also well predicted by the short years. Once again 
Phoenix is the worse case, but the actual difference between the two buildings is less than $3 \%$ of the total. The calculated differences between the townhouse and passive houses are not well represented by the short year. While in no case does the short year prediction reverse the sign of the difference, its magnitude is often significantly in error. The high percentage error in predicting the differences between the various townhouses and the passive houses is caused both by the small magnitude of the differences between these buildings as compared to the differences between the ranch houses and the others, and by the somewhat decreased accuracy of the four-day intervals in predicting the energy requirements of these more massive buildings.

A second set of tests were performed to determine the effectiveness of the short years for predicting the results of varying a single parameter in a building. For this purpose, Fort Meyer Building 219, for which the NBSLD input stream has been published, was chosen. [7] This building is an office of 3265 square feet $\left(303.3 \mathrm{~m}^{2}\right)$ with 13 inch $(.33 \mathrm{~m})$ uninsulated brick walls, an $\mathrm{R} 11\left(.194 \mathrm{~m}^{2}\right.$ $\left.{ }^{\circ} \mathrm{C} \mathrm{W}^{-1}\right)$ ceiling below an attic, 155 square feet $\left(14.4 \mathrm{~m}^{2}\right)$ of glass facing west, and 80 square feet $\left(7.4 \mathrm{~m}^{2}\right)$ facing east. Heating and cooling requirements for this building were calculated with both long and short years for eight orientations. Thus for each run, the building description indicated a rotation of $45^{\circ}$ from the previous analysis. The test was run using TRY tape for Washington, D.C. and the short year tape extracted from it. The calculated results for both long and short years are shown in Figure 23. The RMS error for heating requirements calculated by the short year method is $4.72 \times 10^{6} \mathrm{Btu}\left(4.98 \times 10^{9} \mathrm{~J}\right)$. For cooling the error is $1.58 \times 10^{6} \mathrm{Btu}\left(1.67 \times 10^{9} \mathrm{~J}\right)$. The magnitude of this 
error, however, does not reflect the excellence with which the short year predicts the ordering of the long year results. A better measure of correspondence would be the residual standard deviation of a simple regression of the long versus short year heating or cooling requirements using the long year calculation as the dependent variable. The results of the regression for both heating and cooling are shown in Table 3. The correlation coefficients for heating and cooling are .989 and .990. While the slope coefficients and the intercept show the deviation of the short year heating and cooling requirements from the full year, the low residual standard deviation and the high correlation coefficient show the highly linear relationship between the two sets of results. This linear relationship indicates that prioritization of energy conserving design changes could confidently be performed using the short year method of analysis. Although the coefficients were determined with constant thermostat sectings, they appear to be valid for both setbacks and "dead zone" thermostat strategies.

\section{CONCLUSION}

This report presents a climate data abbreviation technique for reducing the computation and analysis costs of predicting building energy use. The cost reduction should encourage designers to perform more iterative building optimization runs and thereby design more cost effective buildings.

The influence of each climatic variable (temperature, humidity, sun, wind) on building energy use was analyzed by regression from a data base of the energy use of three diverse buildings calculated hourly for three locations across the U.S. These influences are expressed in the form of coefficients in a linear equation used to select short intervals of real weather data from one [or more] full year weather tapes. The short intervals are chosen to represent the longer periods 
(in this case months) with a minimum difference in predicted energy consumption.

The selection algorithm was tested for accuracy by comparing short versus long year heating and cooling calculations for three buildings in six locations, and by using a different building exposed to eight different orientations. The standard error of the short year predictions of the full year calculated heating and cooling requirements is about 3.5 percent of the mean of the total requirements. Variations on monthly basis were wider because of the small sample size. Months with both heating and cooling requirements show the widest percent variations, but the energy contribution of these months to the annual total is of course small. The short year was very successful in predicting the relative energy demands of the different building orientations. This test suggests that the climate abbreviation technique is effective in comparative optimization studies.

Some deviation was noticed in the monthly predictions for the more massive townhouse. Further study is needed to determine the optimum interval lengths for predicting the response for massive buildings with significant thermal lag. The program has been written so that the length of the interval is input by the user.

Abbreviated year weather tapes may be selected using weather statistics representing long term periods of record. In this way the abbreviated year may represent the long term climate better than the source weather data tape. The program offers the user the choice of inputting into the selection algorithm summarized long term averages instead of the usual selection criteria, which are computed from the weather data tape itself. 
Studies are under way to determine whether this program can be used to produce short year tapes which are characteristic of locations other than that of the source weather tape. Currently, hourly weather tapes are available for a limited number of first order weather stations. The abbreviation program could be used to produce short tapes using averages for weather variables from the far greater number of second order stations. The abbreviation program would thereby extrapolate the data from the first order station to the regions surrounding it.

The listing of the interactive selection program is presented in the appendix.

Notes

[1] Private communication with T. Kusuda.

[2] ASHRAE Task Group on Energy Requirements for Heating and Cooling,

"Algorithms for Building Heat Transfer Subroutines", New York, 1975.

[3] G.P. Mitalas, Calculation of Transient Heat Flow Through Walls

and Roofs, ASHRAE Transactions, Vol. 2 1968, p. 185.

[4] T. Kusuda, J.E. Hi11, S.T. Liu, J.P. Barnett and J.W. Bean, Pre

Design Analysis of Energy Conservation Options for a Multi-Story

Demonstration Office Building, Building Science Series 78, National

Bureau of Standards: 1975.

[5] National Climatic Center 1976. Tape Reference Manual, Test Reference

Year, Asheville, N.C.

[6] S.R. Hastings, Three Proposed Typical House Designs for Energy

Conservation Research, NBSIR 77-1309, National Bureau of Standards, 1977. 
[7] T. Kusuda, NBSLD, The Computer Program for Heating and Cooling Loads in Buildings, Building Science Series 69, National Bureau of Standards, 1976 .

[8] B.Y.H. Liu and R.C. Jordan, "The Interrelationship and Characteristic Distribution of Direct, Diffuse and Total Solar Radiation," Solar Energy, Vol. 4, No. 3, July 1960, pp. 1-19.

[9] R. Socolow and R. Sonderreger, Twin Rivers: A Five Year Summary Report, Center for Environmental Studies, Princeton University, Princeton, N.J., 1976.

[10] L.S. Meyer and J. Benjami, 1977. "Modeling Residential Demand for Natural Gas as a Function of the Coldness of the Month," Energy and Buildings, Vol. 1, No. 3 .

[11] E. Dean and A. H. Rosenfield, "Modeling Natural Energy Flow in Houses," Energy and Buildings, Vol. 1, No. 1, Lausanne, Switzerland, 1977.

[12] L. Degelman, A Weather Simulation Model for Building Energy Analysis, ComputerAided Design and Simulation Laboratory, Pennsylvania State University, University Park, Pennsylvania, 1974.

[13] D. Nall and E. Arens, The Influence of Degree Day Base Temperature on Residential Building Energy Prediction, ASHRAE Transaction 1979 Vol. 1. 
TABLE 1. Normalized Coefficients for Weighting Climate Variables

HEATING

Temperature

Cloud Cover

Wind Temperature Product

WASHINGTON, DC

Ranch

.65

.33

Passive

.53

Town

.56

.46

.43

.02

.01

.01

1INNEAPOLIS, MN

Ranch

Passive

Town

PHOENIX, AZ

Ranch

Passive

Town

.69

.56

.54

.65

.57

.57
.34

.42

.42

.01

.01

.01

COOLING
.01

.01

.02
.30

.43

.44

WASHINGTON, DC

Ranch

Passive

Town

1INNEAPOLIS, MN

Ranch

Passive

Town

PHOENIX, AZ

Ranch

Passive

Town

Ave rage
.75

.60

.60

.68

.57

.52

.65

.51

.57

.60
.24

.39

.39

.01

.01

.01

.31

.42

.47

.01

.01

.01

.01

.34

.02

.47

.01

.42

.

.39

.01 
TABLE 2. Long Versus Short year Prediction of Energy Usgae Differences Between Buildings in Btu $\times 10^{4}$

\section{$\frac{\text { BOSTON }}{\text { Long }}$ \\ Short}

Error (\%)

\section{COLUMBIA}

Long

Short

Error (\%)

MINNEAPOLIS

Long

Short

Error (\%)

$\frac{\text { MIAMI }}{\text { Long }}$

Short

Error (\%)

PHOENIX

Long

Short

Error (\%)

\section{WASHINGTON}

Long

Short

Error (\%)

$\underline{\text { Ranch }} \quad \underline{\text { Passive }} \quad \underline{\text { Town }} \begin{aligned} & \text { Ranch to } \\ & \text { Passive }\end{aligned}$

3712.5

3706.7

2202.2

2119.4

3707.6

3563.3

2539.6

2342.3

4165.7

4268.9

5989.8

3262.1

3837.4

3683.1

3296.6
3343.7

3187.6

3193.3

2862.6

2743.8
1973.5

1791.9
2626.6

2639.8

2935.1

2818.1

$\begin{array}{r}-1168.0 \\ -1221.0 \\ \hline 4.5\end{array}$

395.5

$\frac{475.8}{20.3}$

4705.1

4553.1

$\begin{array}{r}-1930.1 \\ -1720.1 \\ \hline-10.8\end{array}$

3899.1

3764.1

$\begin{array}{r}446.9 \\ 421.0 \\ \hline-5.7\end{array}$

3205.8

3263.2

Passive

to Town

424.4

$\frac{520.4}{22.6}$

1085.9

$\frac{1066.9}{1.7}$

772.5

$\frac{745.2}{3.5}$

1390.7

$\frac{1436.7}{3.3}$

$\frac{-284.2}{-47.3}$

508.1

$\frac{502.0}{-1.2}$

$\frac{81.0}{31.3}$

18.2

90.8

$\begin{array}{r}109.0 \\ 150.4 \\ \hline 38.0\end{array}$

$\begin{array}{r}69.9 \\ \hline 284.0\end{array}$

$\frac{80.5}{-11.3}$

2310.7

2182.3 $\begin{array}{r}889.1 \\ 951.9 \\ \hline 7.1\end{array}$

337.2

$\frac{390.4}{15.8}$
551.9

$\frac{561.5}{1.7}$ 
TABLE 3-A. Heating Regression Results Fort Meyer Building

Least Squares Fit of Response (Short Year Results) as a Linear Function of a Constant and an independent Variable (Long Year Results)

Estimates from Least Squares Fit

Indep Var.

Constant*

Long year Results

\section{Coefficient}

$-9.9897470$

1.0445478

\section{S.D. of Coefficient}

$$
7.6137124
$$

.064406681

$-1.31$

16.22
Accuracy*

5.46

6.54
Residual Standard Deviation =

Based on Degrees of Freedom

Mean of Response
.15556847

$8-2=6$

118.21

TABLE 3-B. Cooling Regression Results

Fort Meyer Building

Least Squares Fit of Response (Short Year Results) as a Linear Function of a Constant and an Independent Variable (Long Year Results)

\section{Estimates from Least Squares Fit}

\begin{tabular}{|c|c|c|c|c|}
\hline Indep Var. & Coefficient & S.D. of Coefficient & Ratio & Accuracy* \\
\hline Constant* & -7.0866289 & 2.2362117 & -3.17 & 6.09 \\
\hline Long Year Results & 1.1702253 & .068947535 & 16.97 & 6.82 \\
\hline $\begin{array}{l}\text { Residual Standarc } \\
\text { Based on Degrees } \\
\text { Mean of Respons }\end{array}$ & $\begin{array}{l}\text { ion }= \\
\text { edom } \\
=\end{array}$ & $\begin{array}{l}.16491220 \\
8-2=6 \\
32.42\end{array}$ & & \\
\hline
\end{tabular}

* The coefficient for the constant is the intercept for the linear model. The The coefficient for the long year results as the slope for the linear models. 

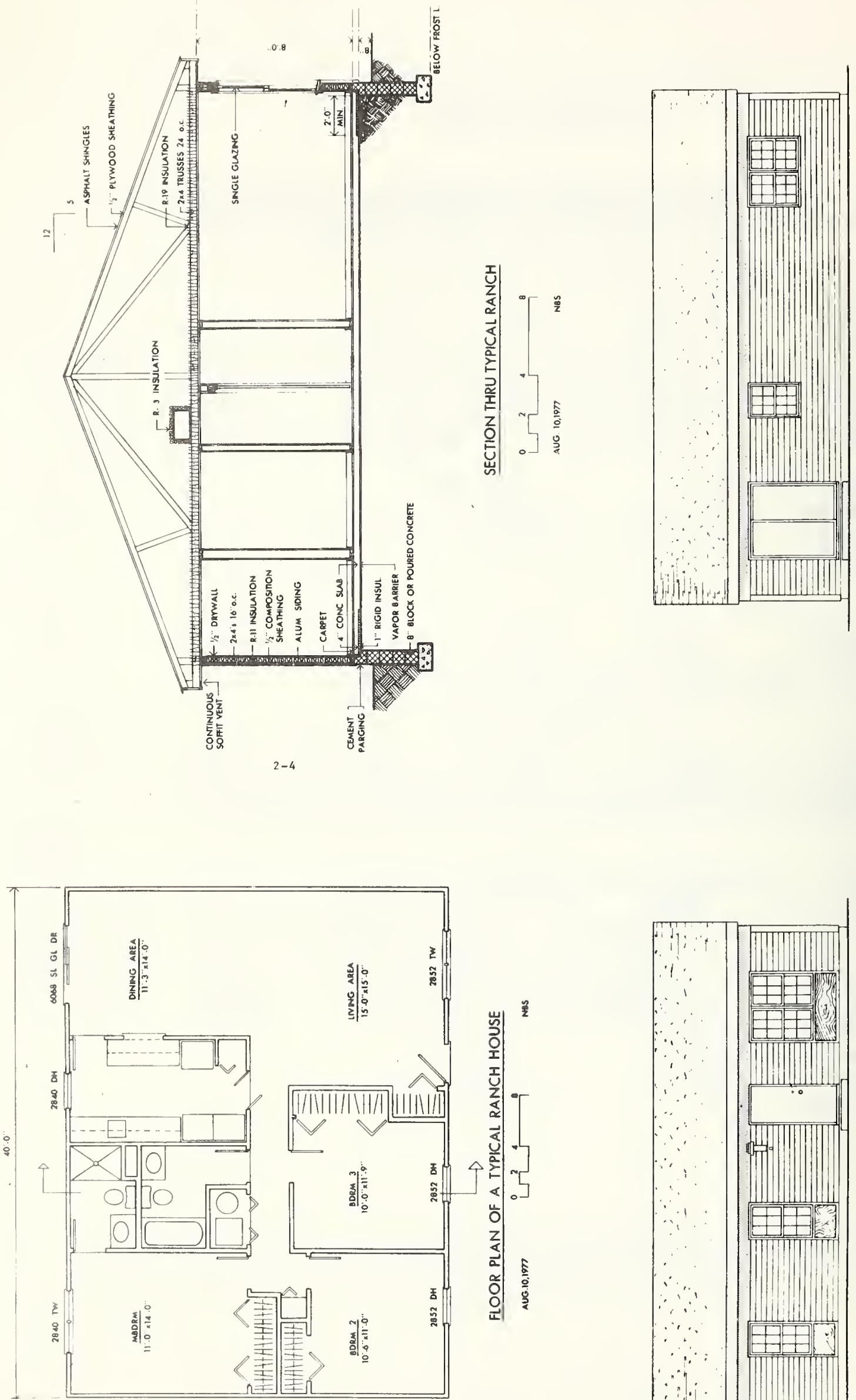

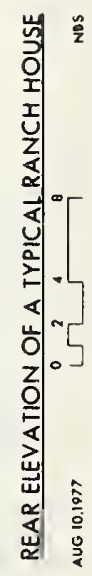

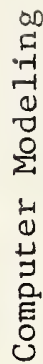

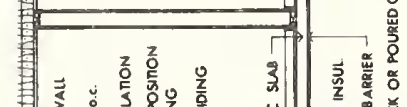

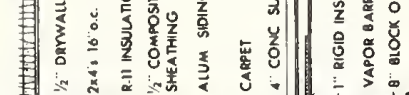

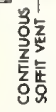

氧蛋
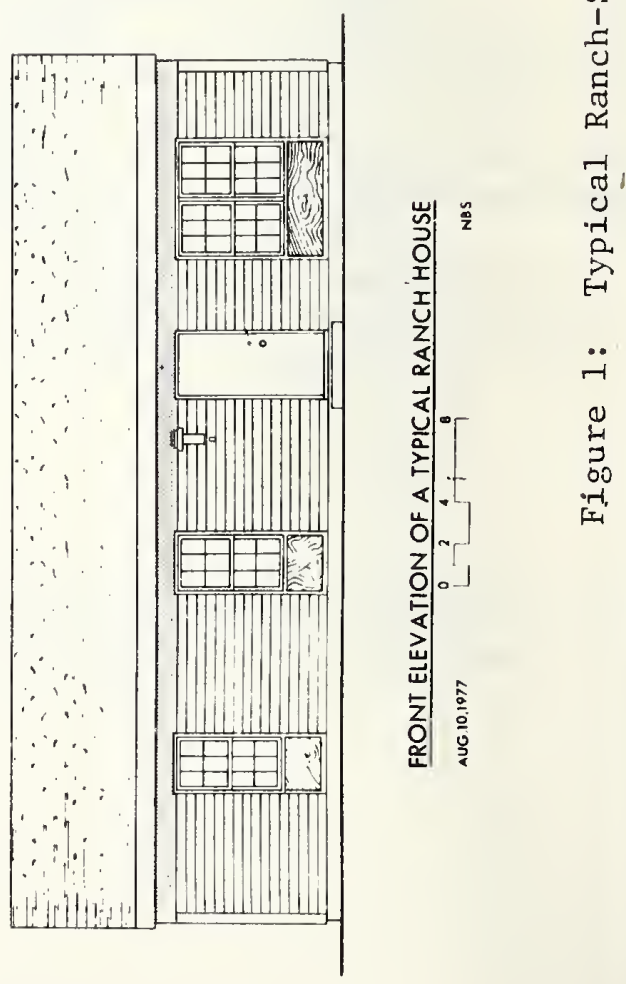

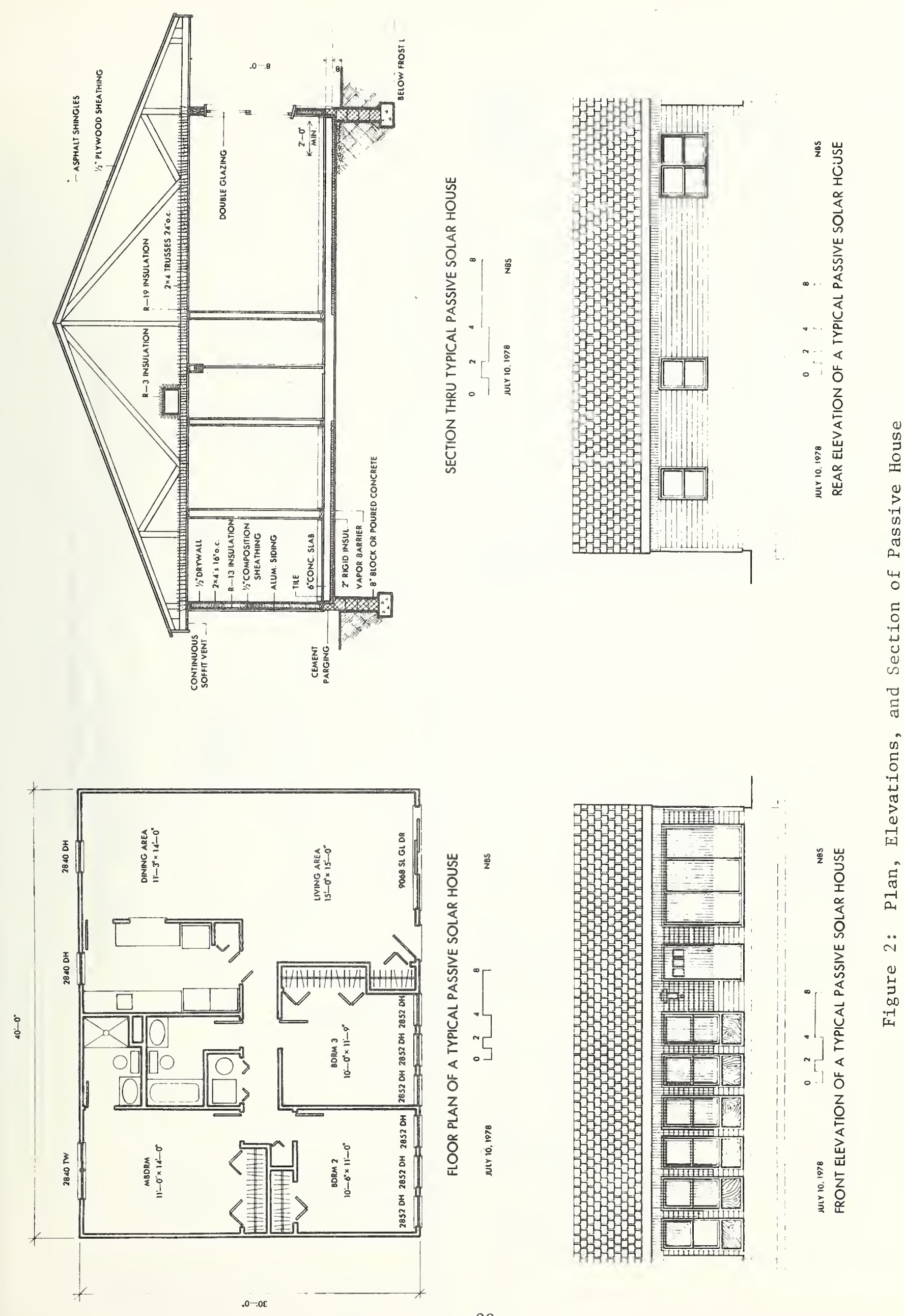

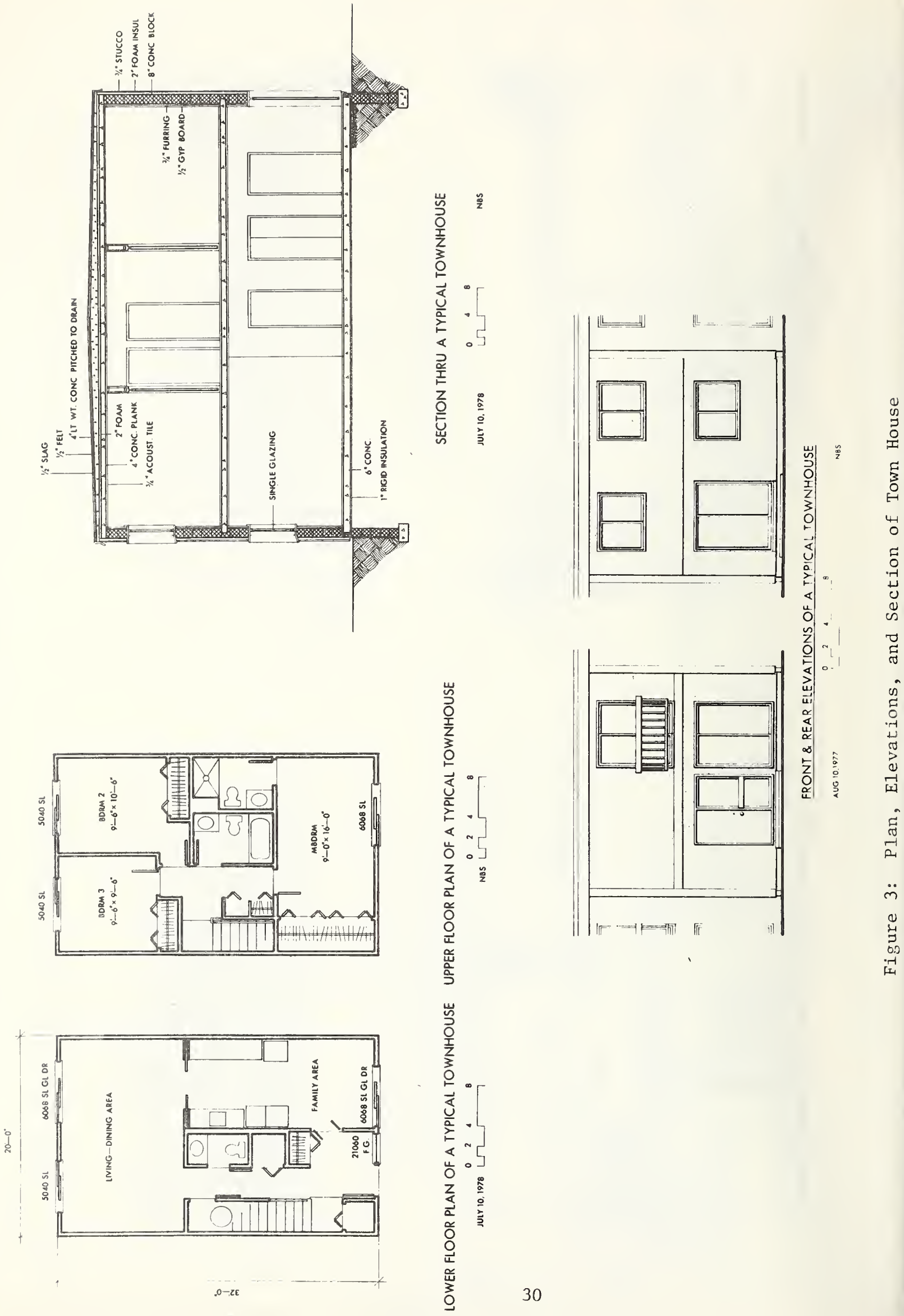


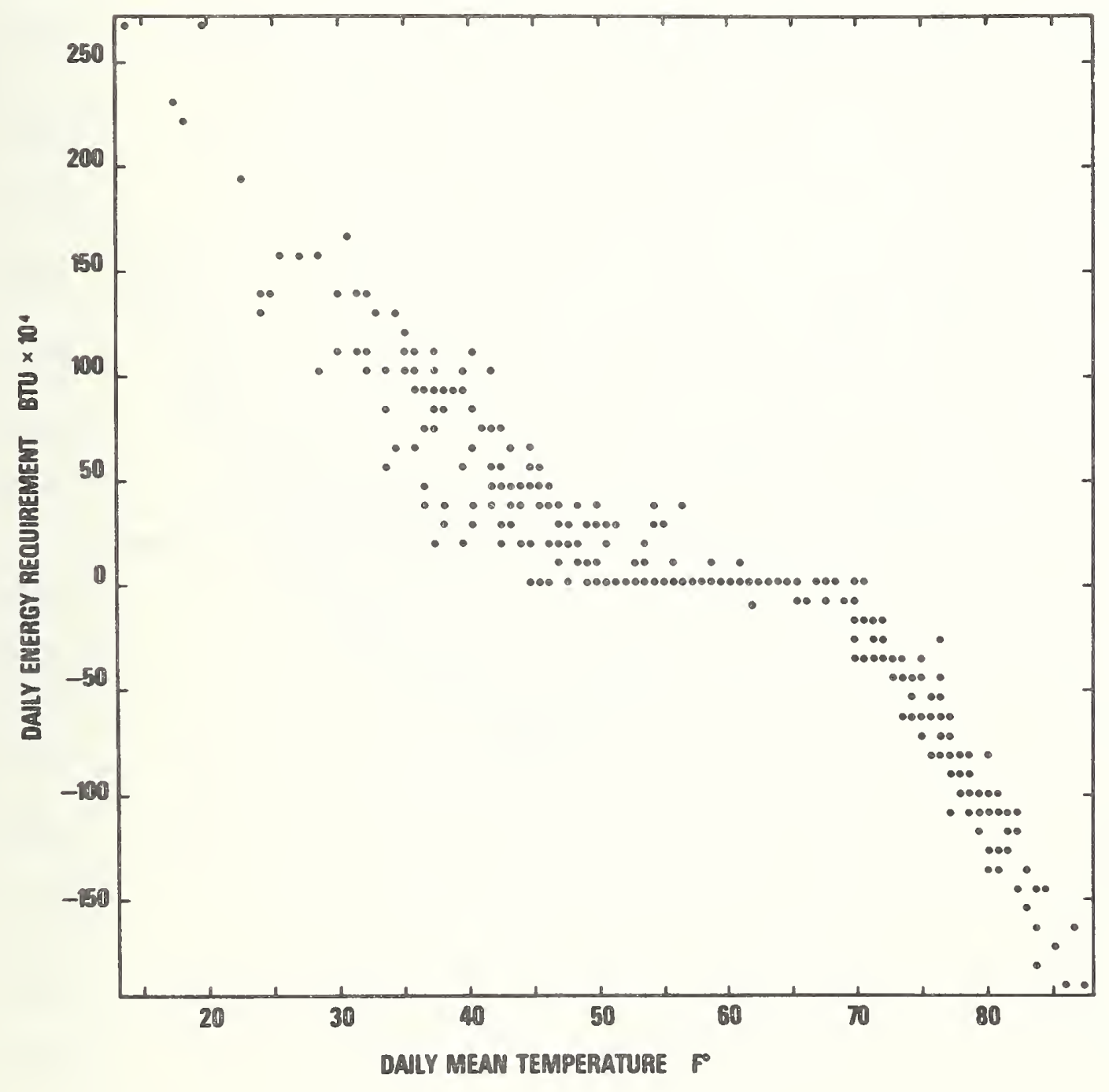

Figure 4: Daily Mean Temperature to Daily Heating and Cooling Requirements 


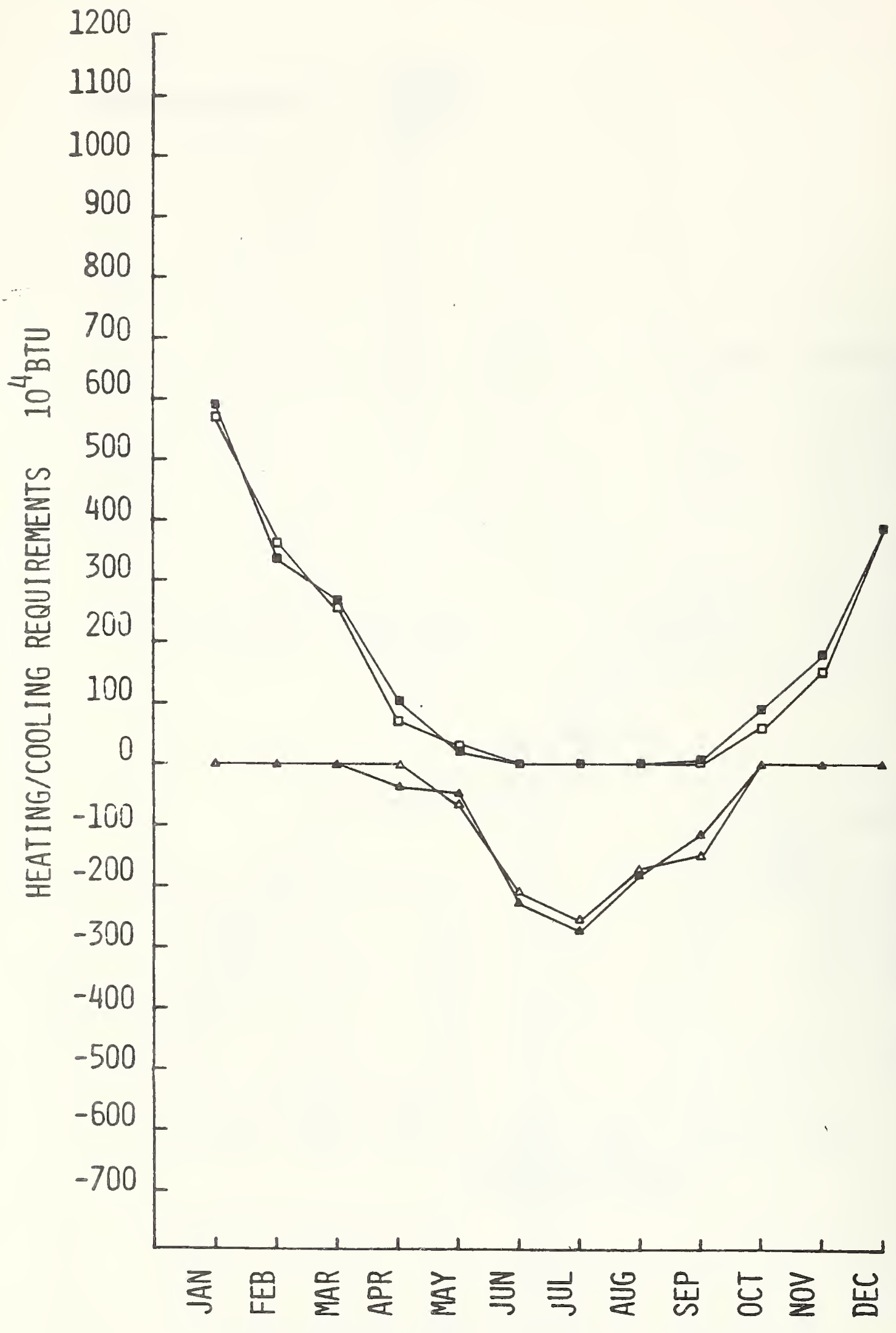

FULL YEAR 


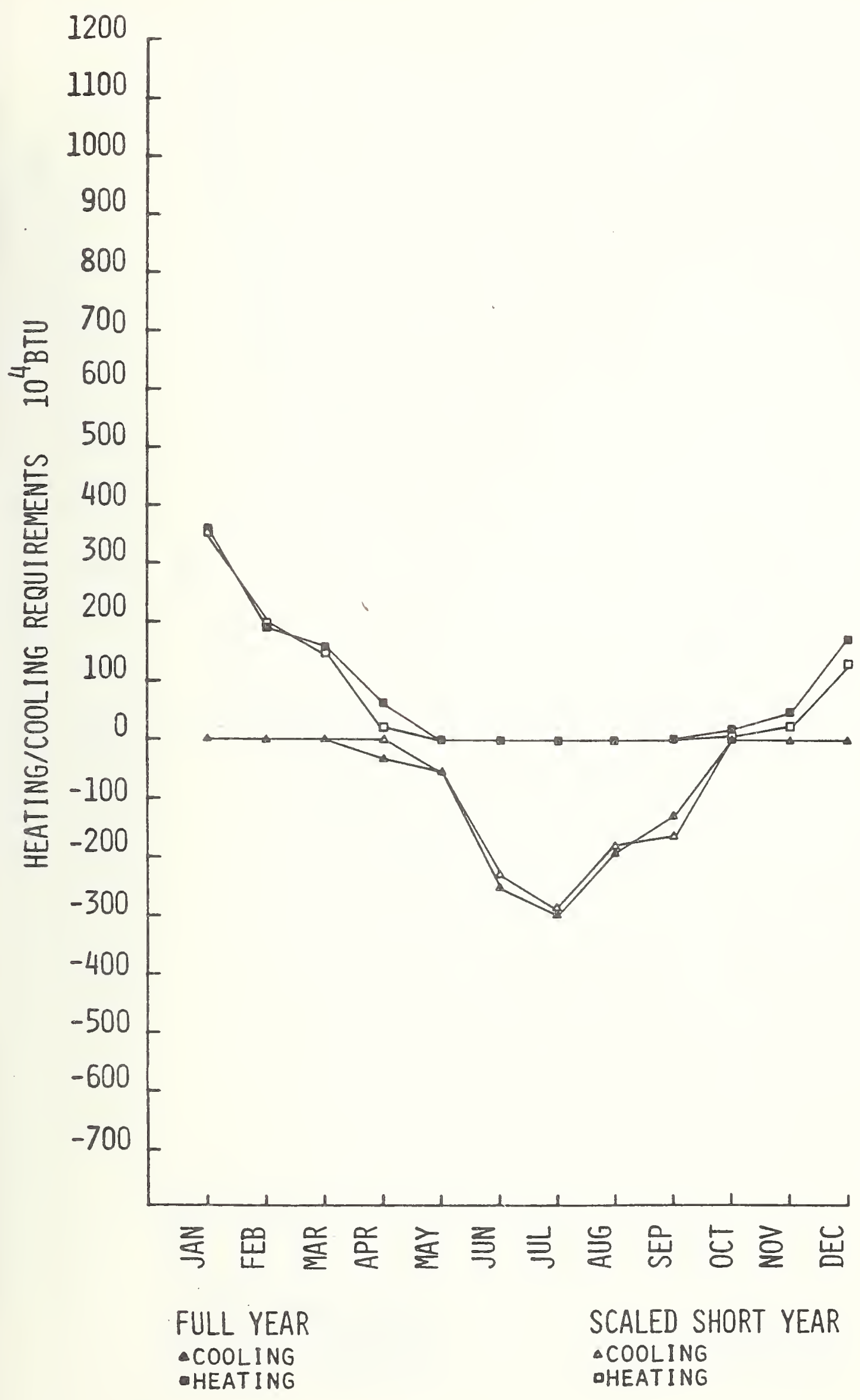

Figure 6. Washington Passive House 


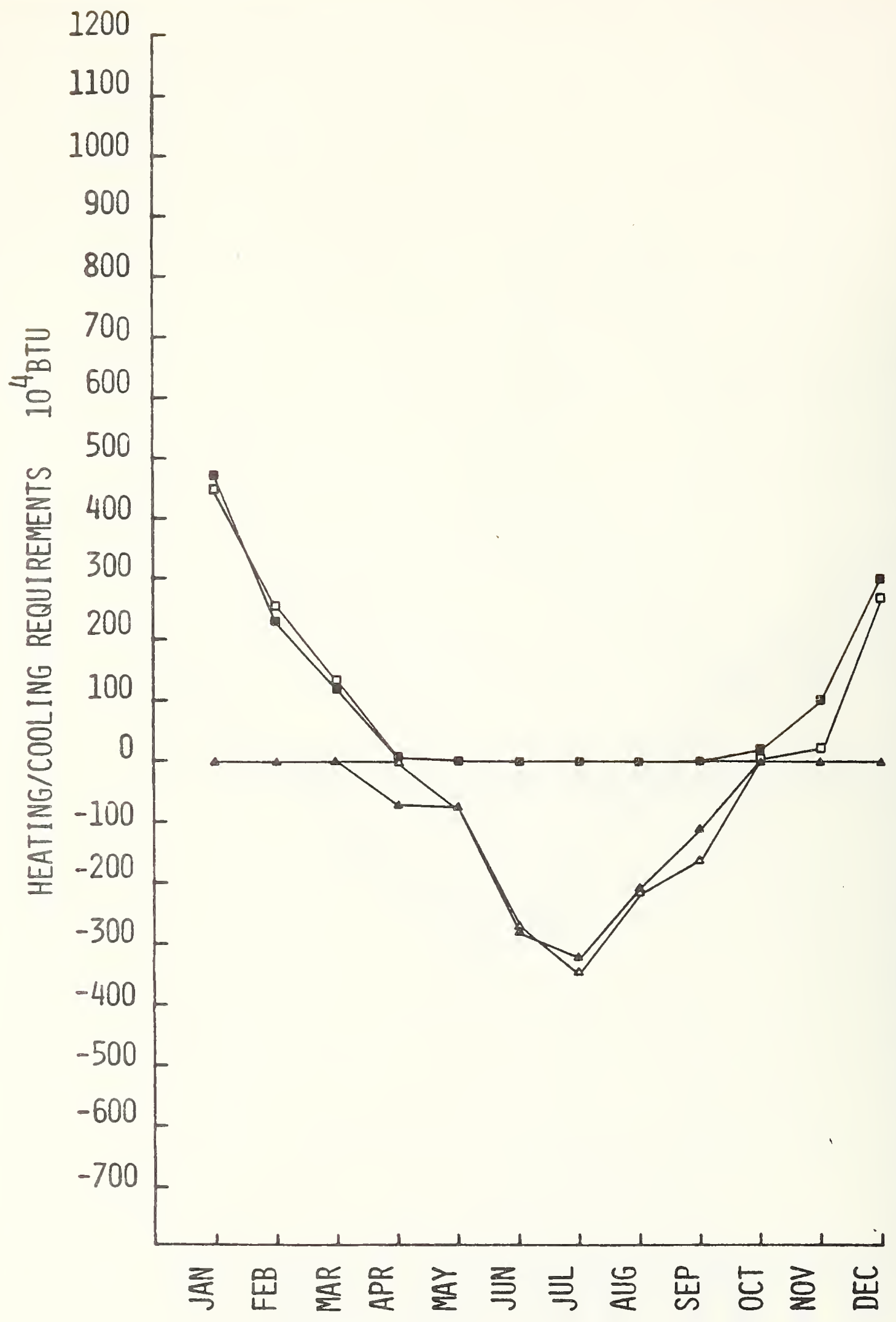

FULL YEAR

- COOLING

- HEATING

SCALED SHORT YEAR $\triangle$ COOLING DHEATING 


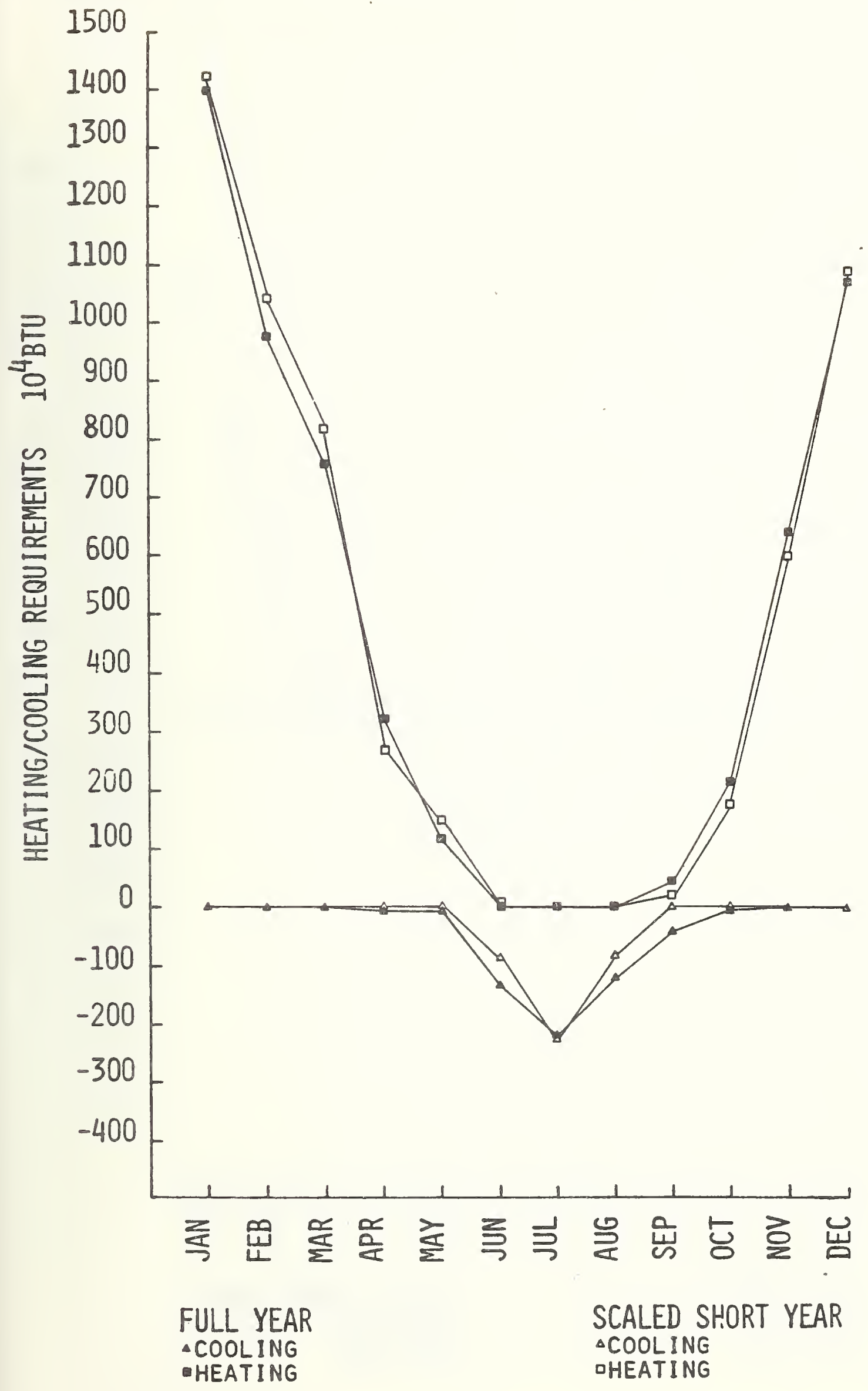




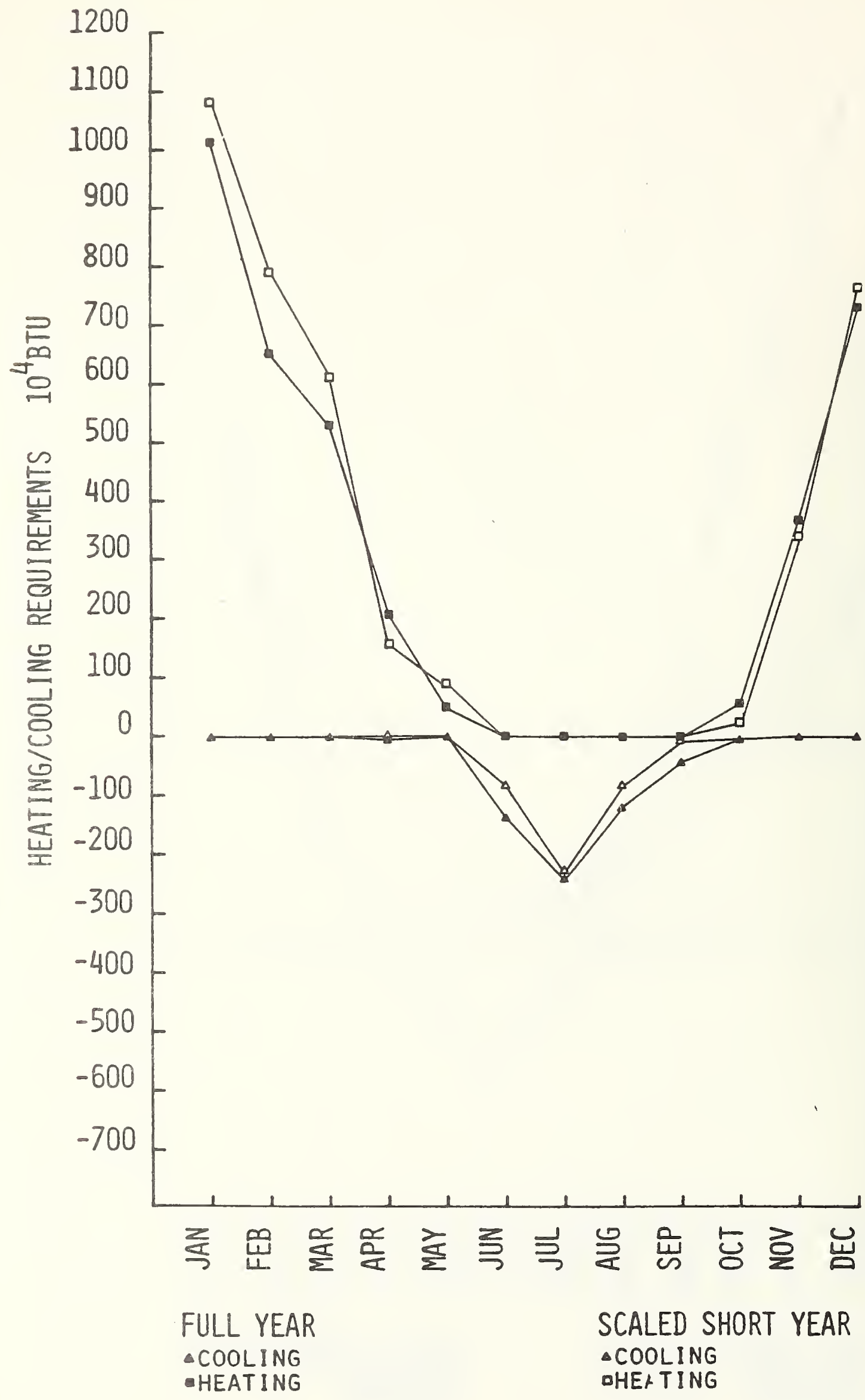

Figure 9. Minneapolis Passive House 


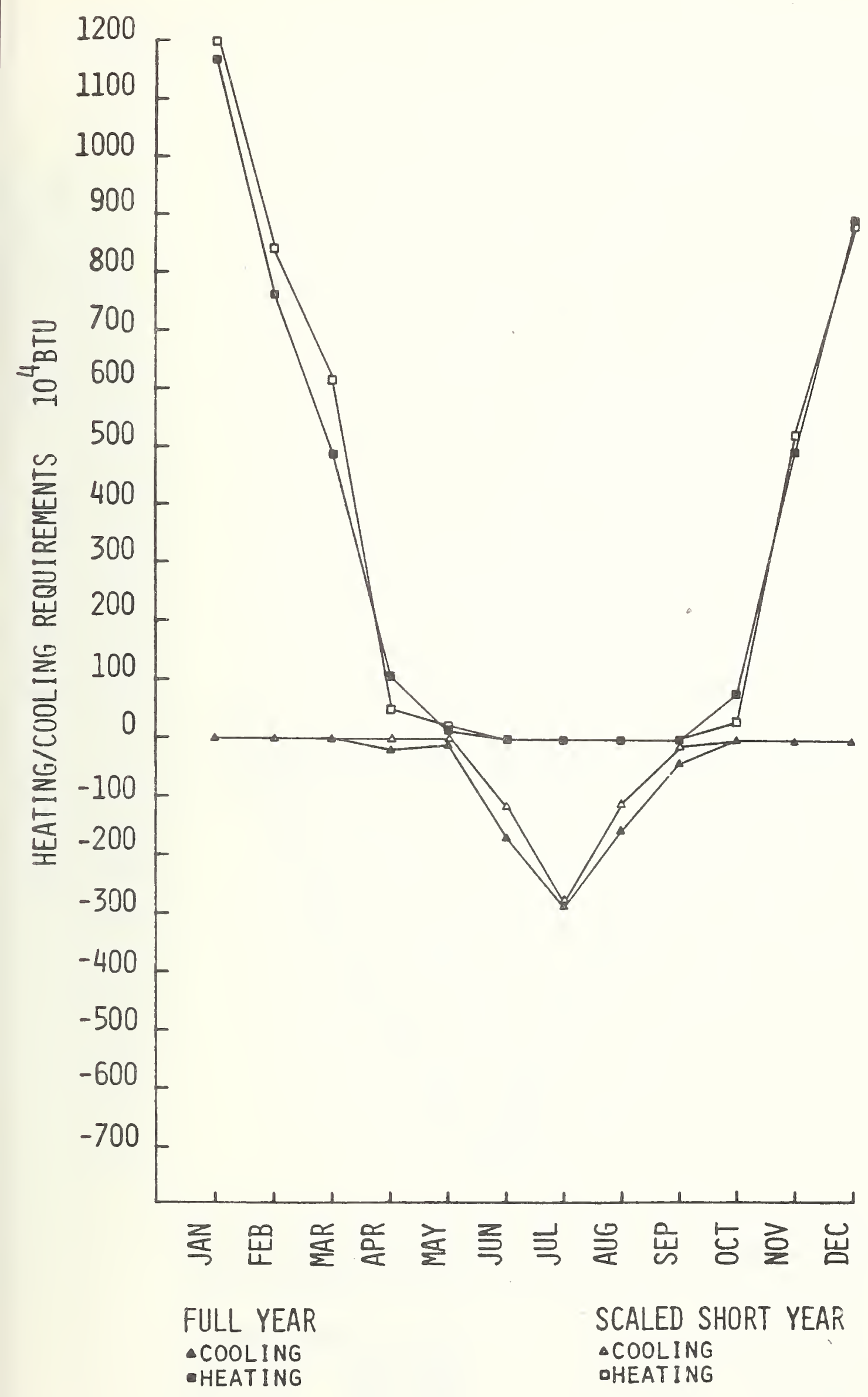




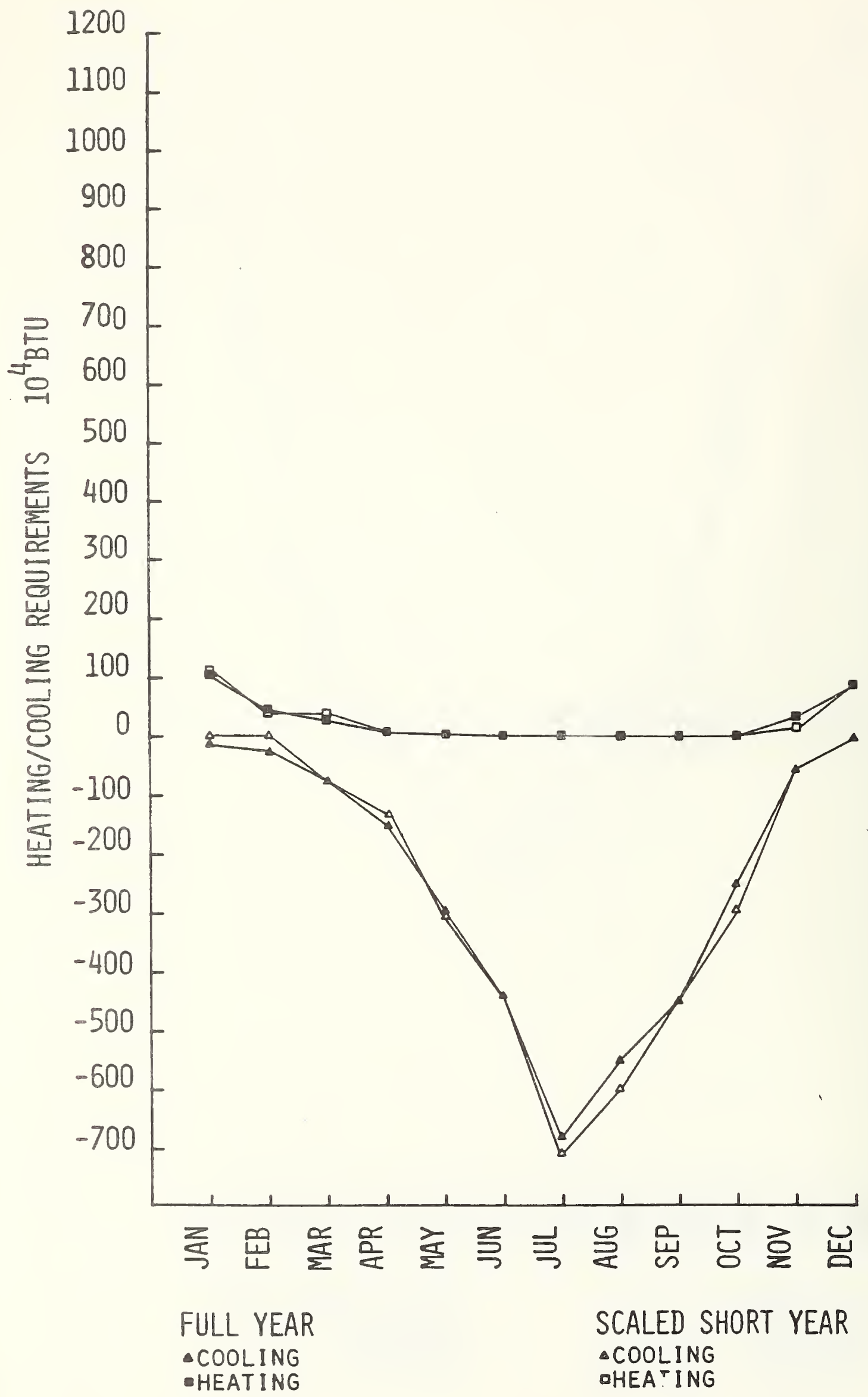

Figure 11. Phoenix Ranch House 


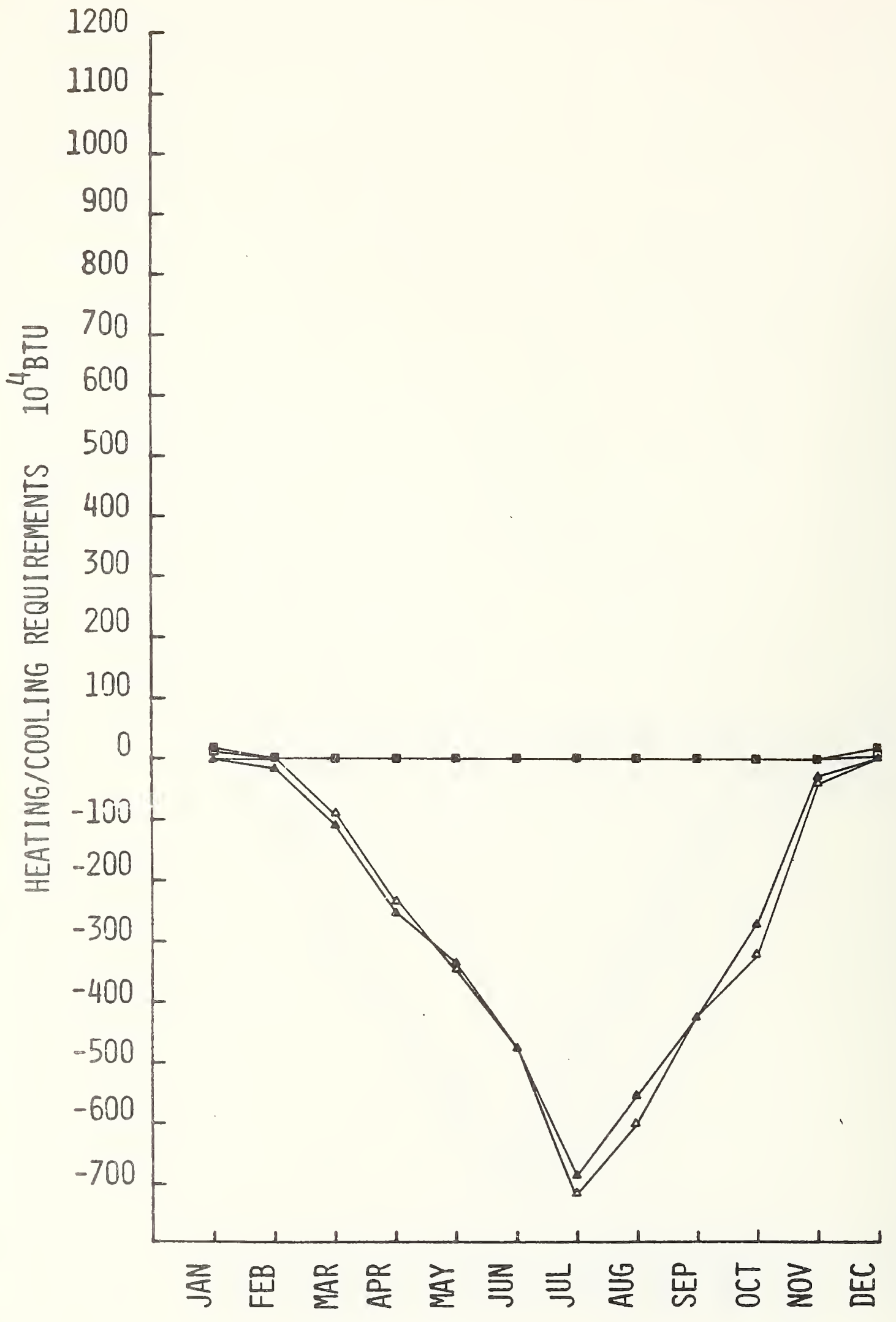

FULL YEAR $\triangle$ COOLING - HEATING
SCALED SHORT YEAR $\triangle$ COOLING DHEATING 


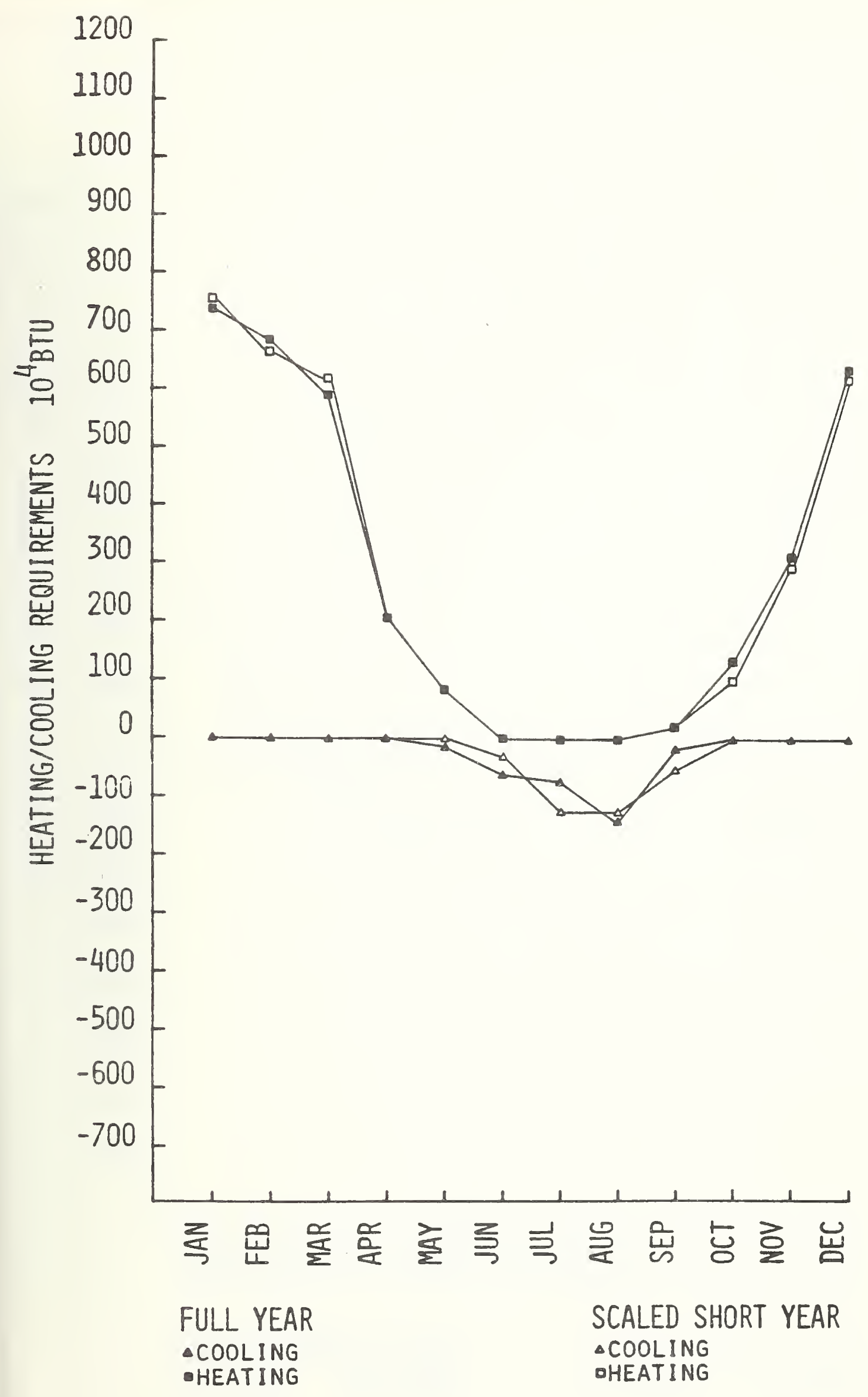

Figure 14. Boston Ranch House 


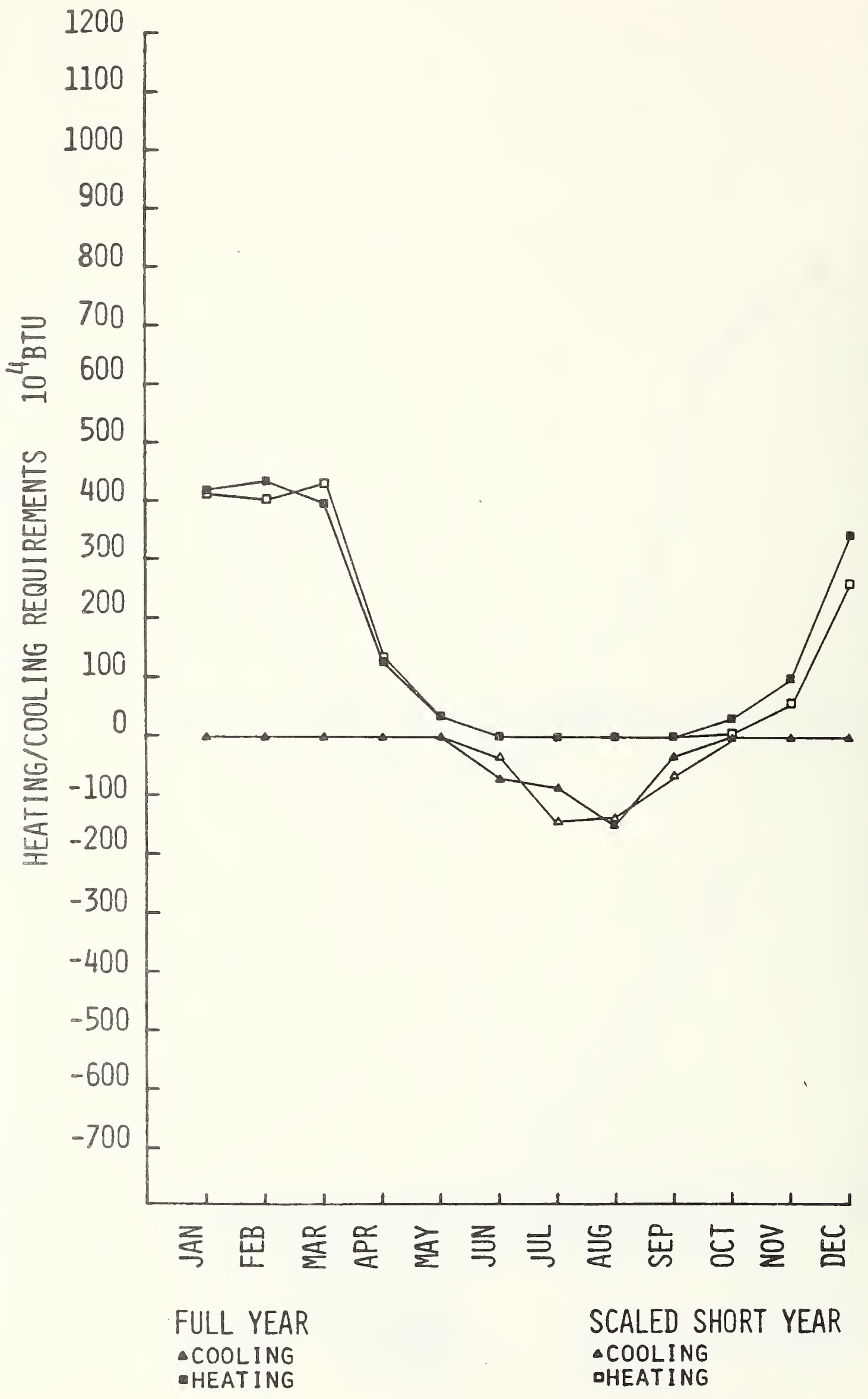




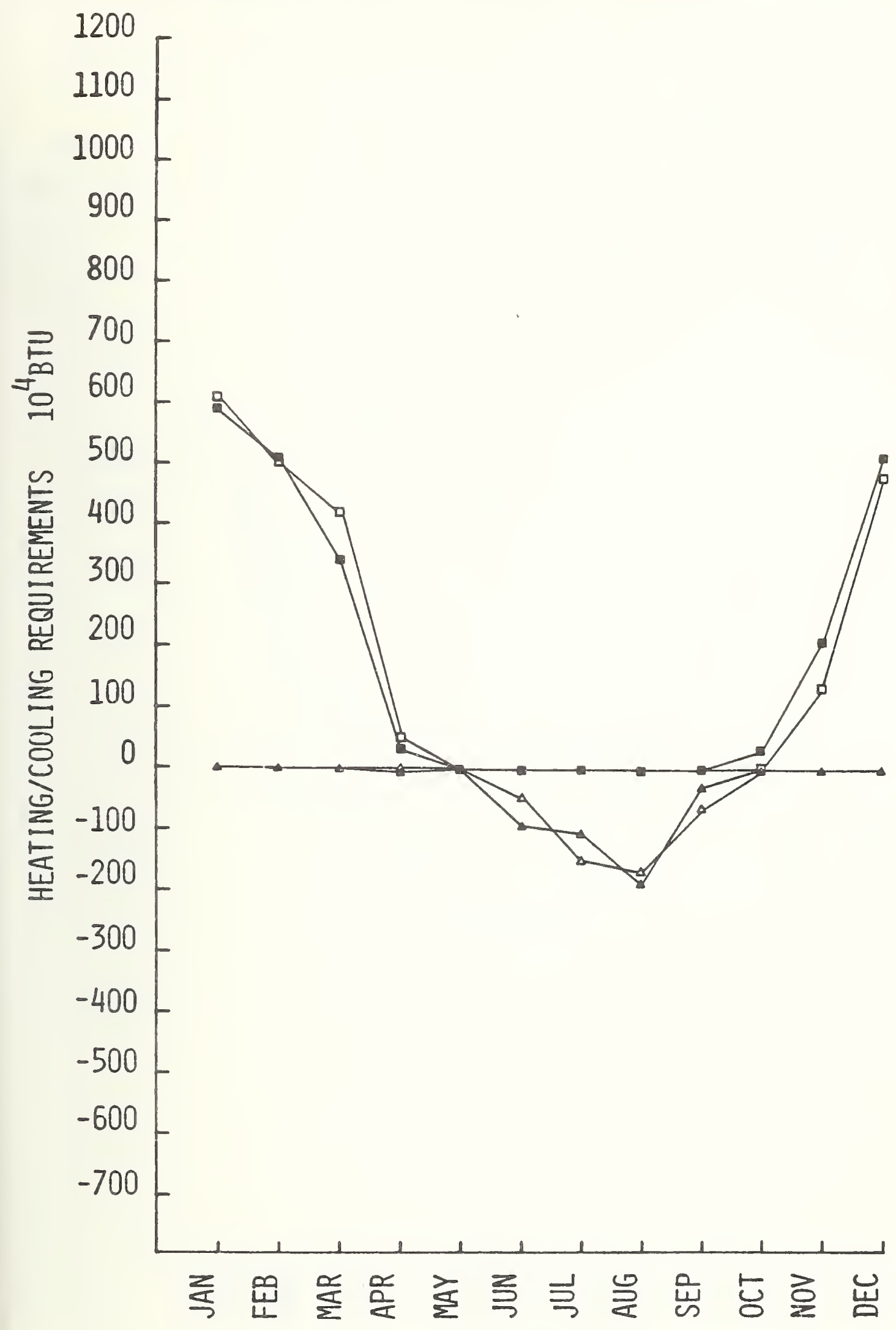

FULL YEAR

SCALED SHORT YEAR

-COOL:NG

- HEATING 


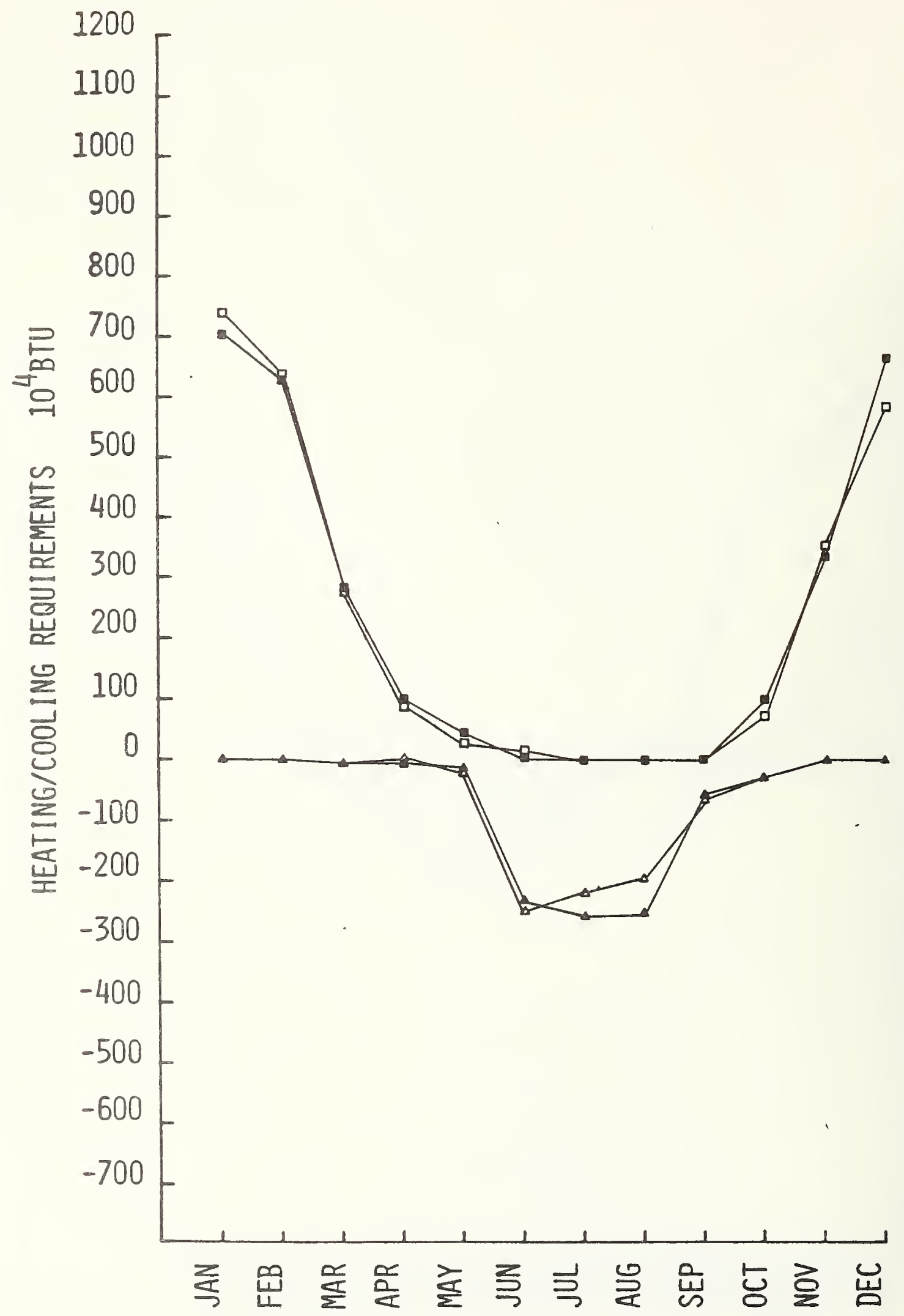

FULL YEAR 


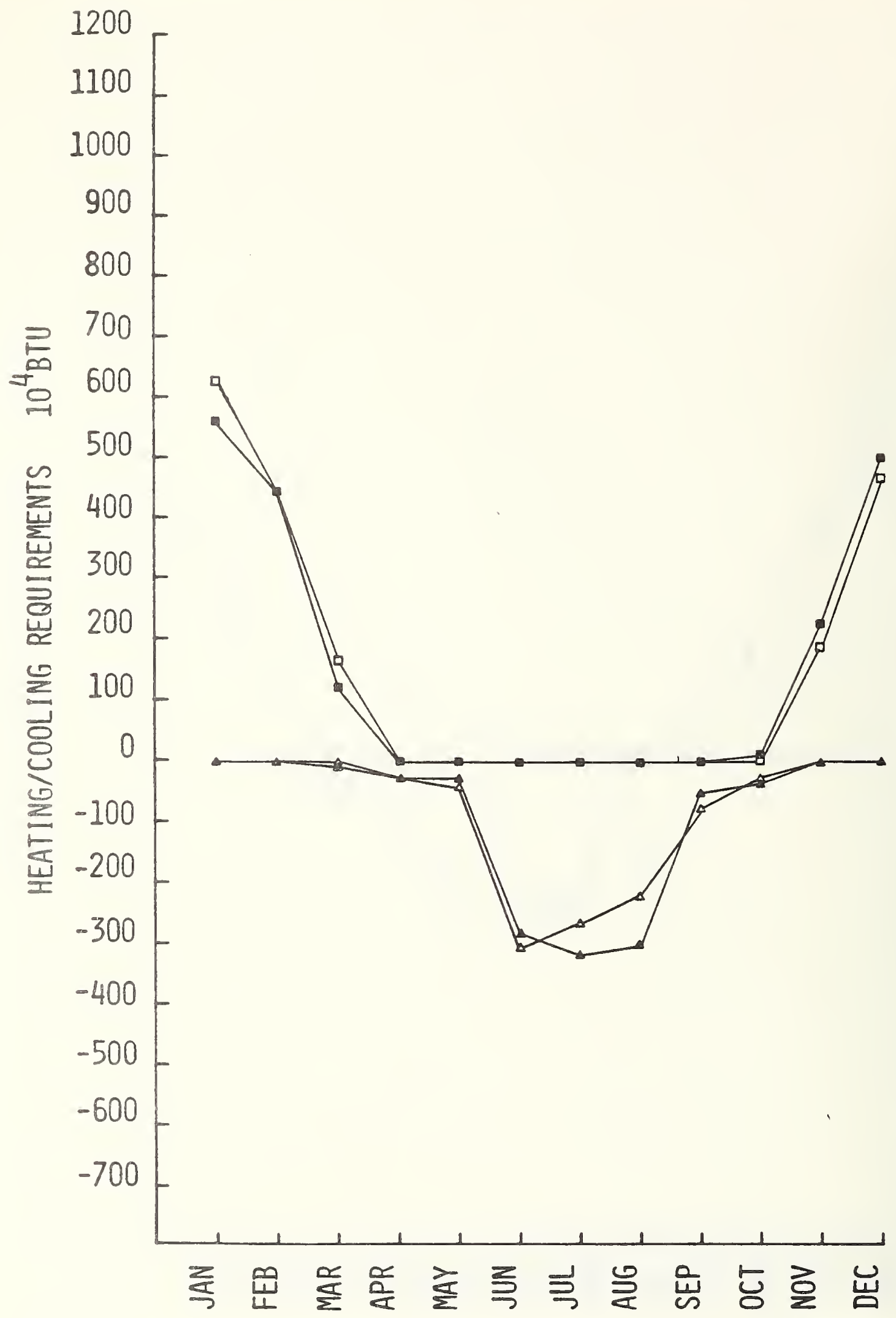

FULL YEAR

$\triangle$ COOLING

- HEATING

SCALED SHORT YEAR - COOLING DHEATING 


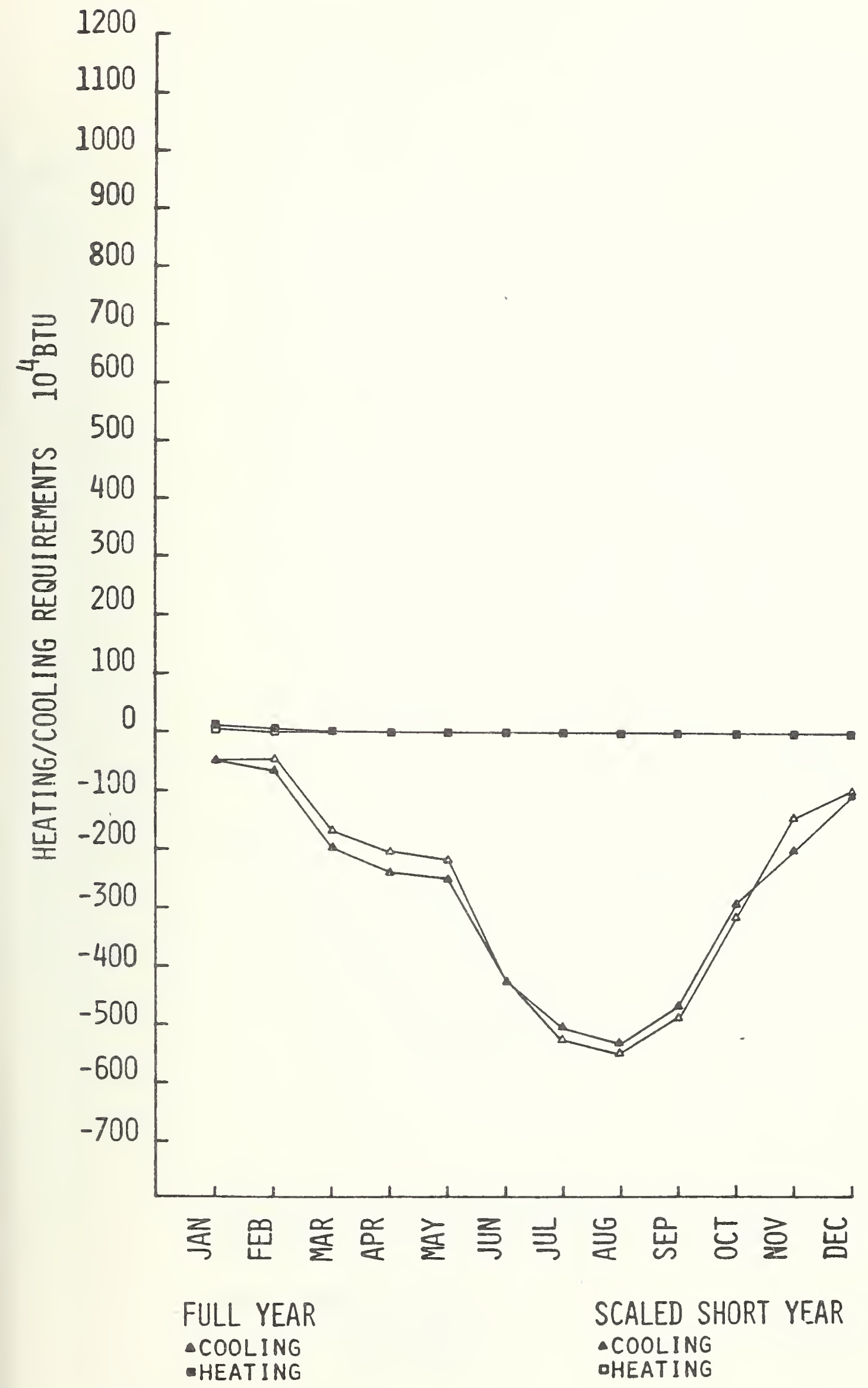




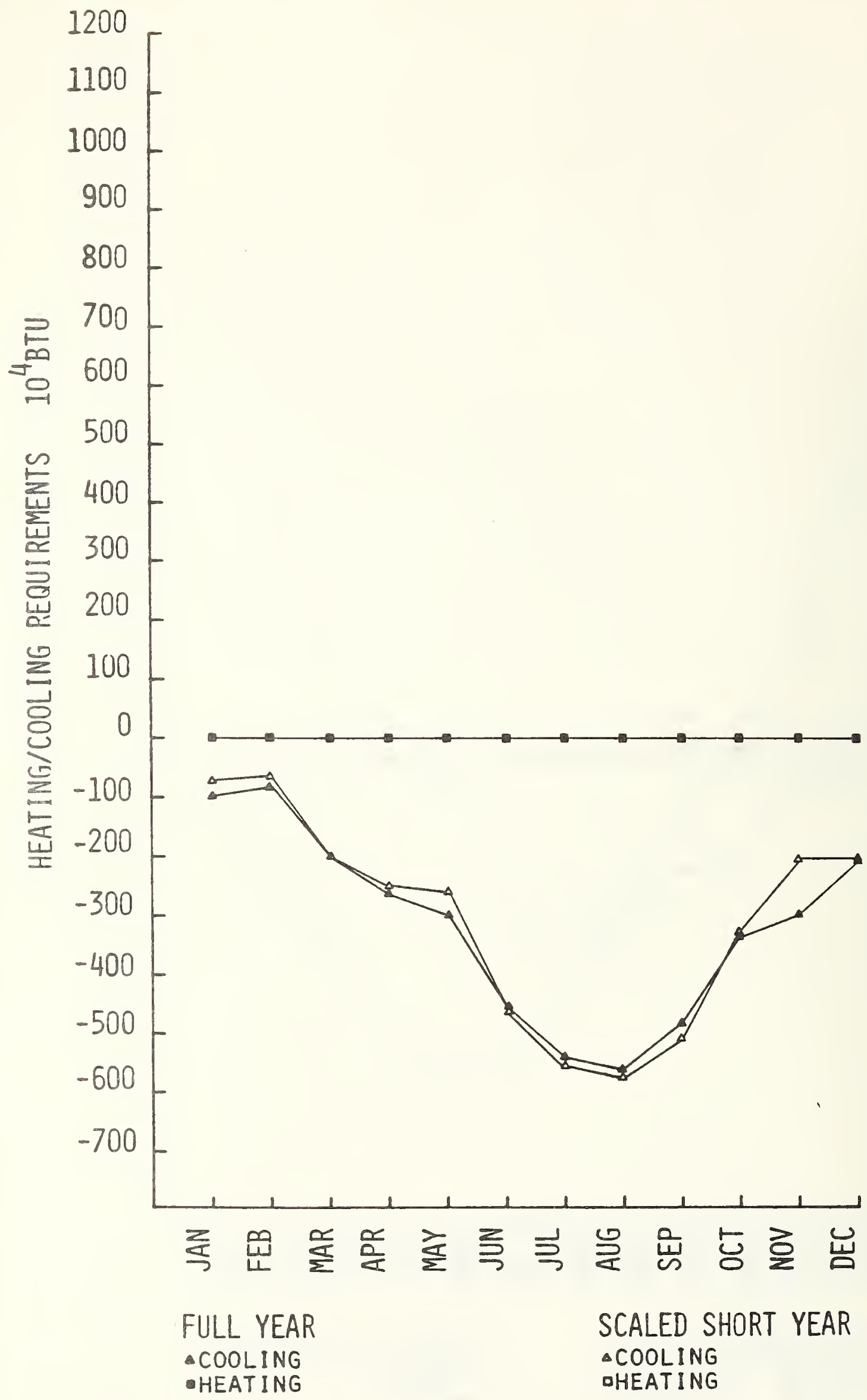




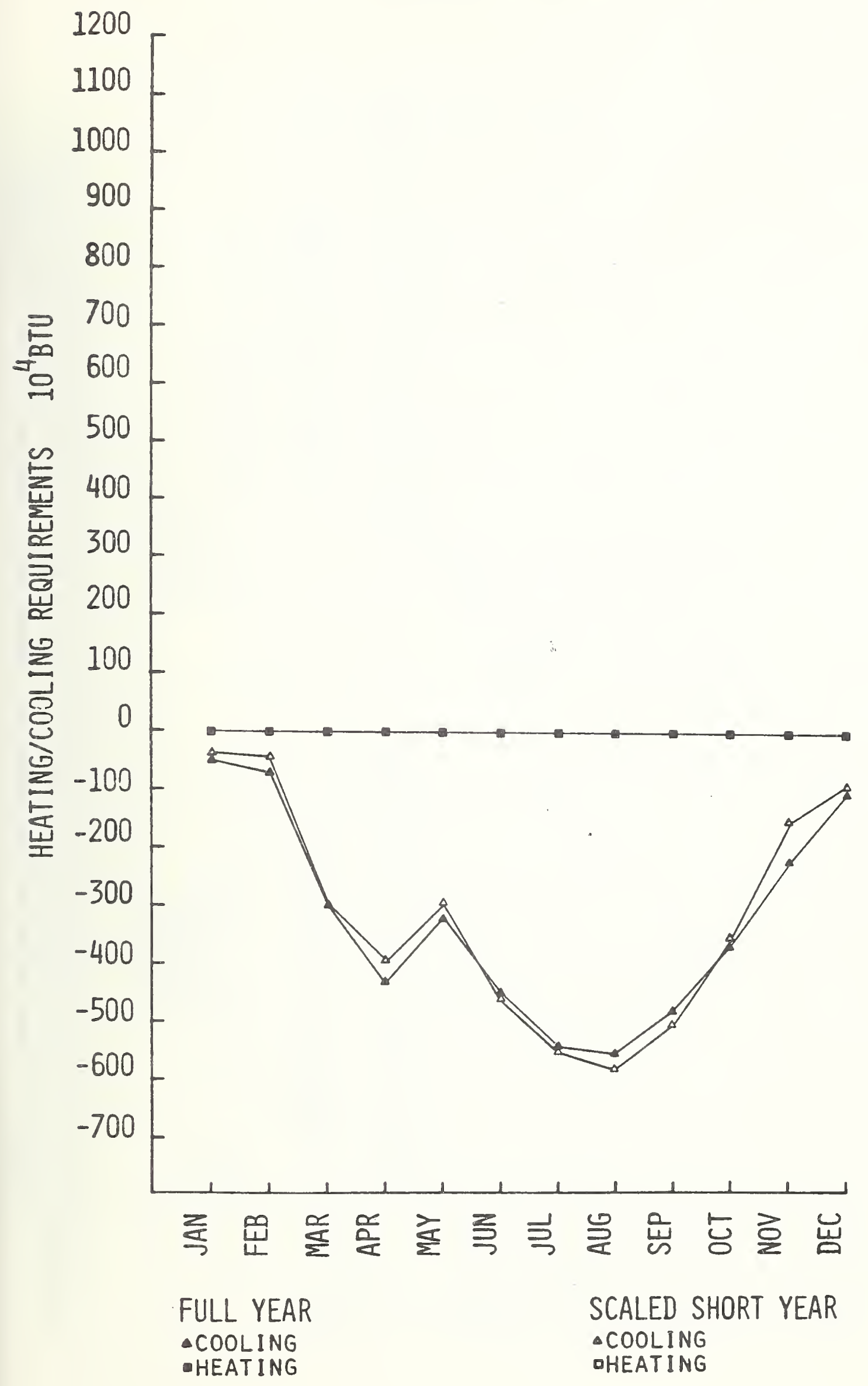



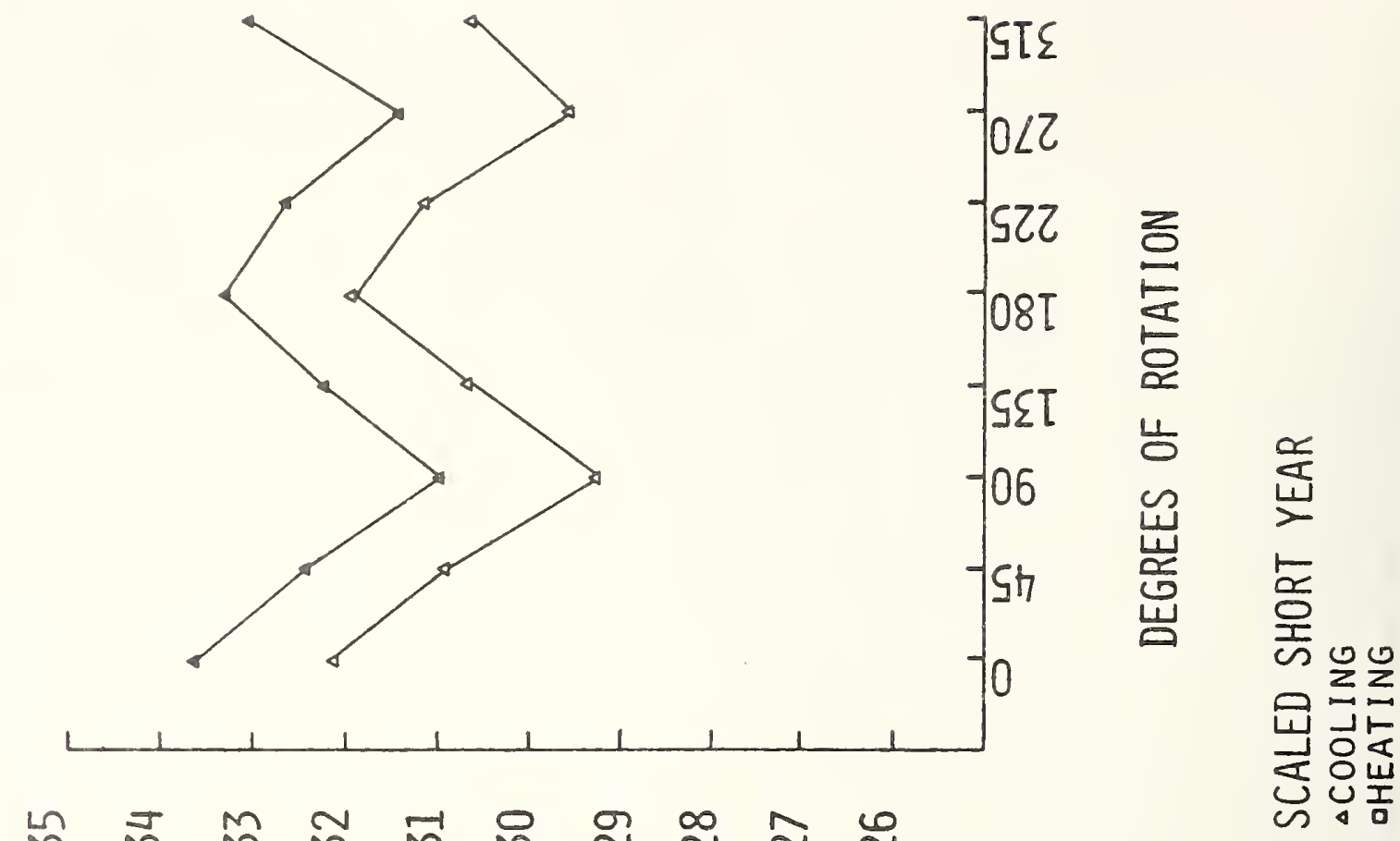

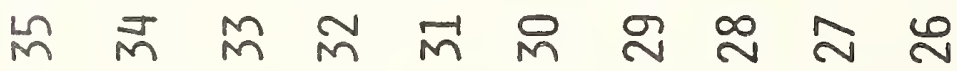

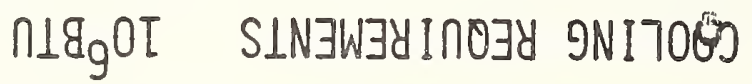
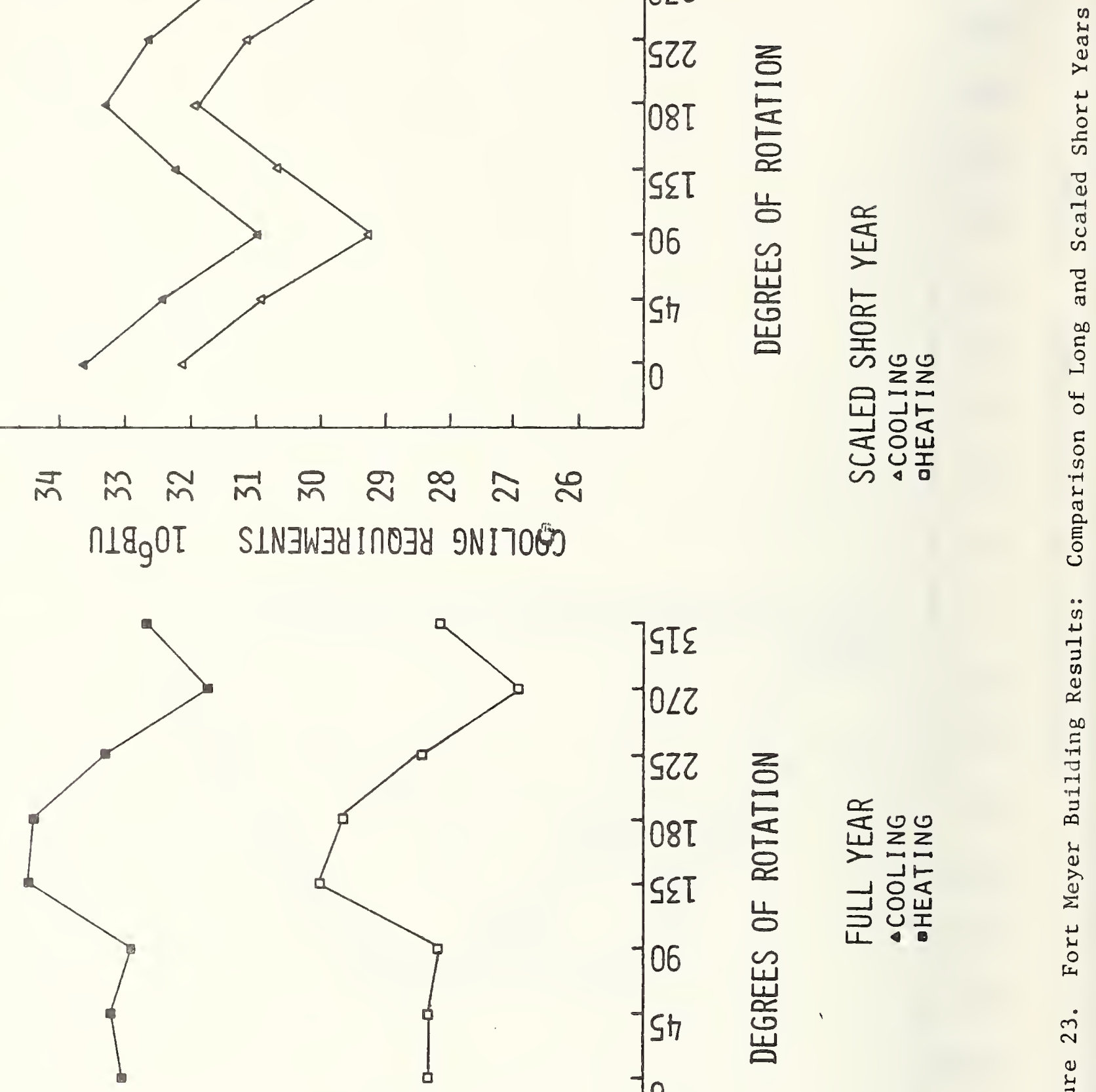

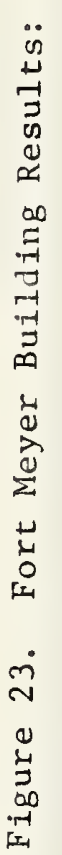

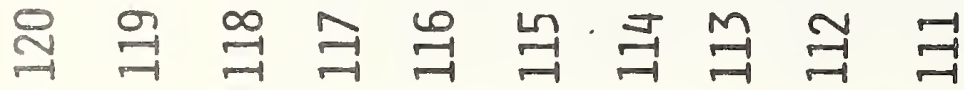

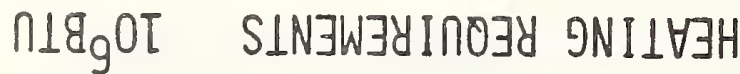


APPENDIX: Listing of Program to Select and Create Abbreviated Weather Years.

C

c

c

c

c

C

c

c

$c$

C
* SELECT*

MAIN FOUTINE OF A PROGRAM TE ABBREVIATE YEAR-LENGTH WEATHERTAPES BY SELECTING SHORT CONTIGUOUS INTERVALS OF DAYS TO REPRESENT EACH MONTH.

USE LOGICAL UNIT 8 TO INPUT FULL-YEAR WEATHER FILE IN NBSLD FORMAT. USE LOGICAL UNIT 9 TO WRITE SHORT-YEAR WEATHER FILE.

THE INTERVALS ARE PRINTED FOR EVALUATION ACCORDING TO THREE TYPES OF RANKING SYSTEMS:

TYPEO RANKS INTERVALS BASED ON THEIR DRY BULB AVERAGE TEMPERATURE ALONE.

TYPEI RANKS INTERVALS BASED ON THE REGRESSION FORMULA.

TYPE2 RANKS INTERVALS BASED ON THE FORMULA ADJUSTED FOR INTERVAL TOTAL DRY BULB TEMPERATURE RANGE .

THE SHORT-YEAR FILE IS CREATED FROM TYPEZ ONLY IN THIS PROGRAM.

VARIABLES IN ORDER DF LISTING:

DLTADB:

DIFFERENCE IN DRY BULB AVERAGE TEMPERATURE GETHEEN INTERVAL AND MONTH. F.

DLTADR: DIFFERENCE IN DRY BULB RANGE BETWEEN INTERVAL AND MONTH, F。 WSDBSP: AVERAGE WINDSPEEO-TEMPERATURE-PRODUCT OF INTERVAL, $F$ MPH.

CCSPAN: AVERAGE CLOUD COVER FOR INTERVAL, TENTHS.

DBSPAN: AVERAGE DRY BULB TEMPERATURE FOR INTERVAL. F.

SRANGE: DRY BULB TEMPERATURE RANGE OF INTERVAL. F.

NDAY:

DAVG:

NUMBER OF DAYS IN MONTH.

DAILY AVERAGE DRY BULB TEMPERATURE, F.

DAILY DRY BULB TEMPERATURE RANGE, F.

MONTHLY MAXIMUM DRY BULB TEMPERATURE, F. MONTHLY MINIMUM DRY BULB TEMPERATURE, F.

DAILY CLOUD COVER, TENTHS.

DAILY MAXIMUM DRY BULB TEMPERATURE, F.

DAILY MINIMUM DRY BULB TEMPERATURE, F.

DAILY WINDSPEED-DRY-BULB-TEMPERATURE-PRODUCT, F $X$ MPH. SUM OF HOURLY MOISTURE RATIOS FOR DAY, LB HZO VAPOR PER LB DRY AIR.

RANK OF INTERVAL ACCORDING TO FORMULA.

RANK 1:

RANK ACCORDING TO GREATEST TEMPERATURE RANGE.

DAILY AVERAGE CLOUD COVER DURING SUNLIT HOURS. TENTHS.

CCAOY:

CCADSP:

AVERAGE SUIVLIT CLOUD COVER FOF INTERVAL, TENTHS.

DIFFERENCE IN SUNLIT CLOUD COVER FOR INTERVAL AND MONTH, TENTHS.

DLWSDB: DIFFERENCE IN WINDSPEED-TEMPERATURE-PRODUCT FOR TNTERVAL. $F \times$ MPH.

WASP:

AVERAGE CF DAILY MOISTURE-RATIO-SUMS FOR INTERVAL, LB H2.O VAPOR PER LB DRY AIR. 


\begin{tabular}{|c|c|c|c|}
\hline 58 & c & DLWA: & IOISTURE-RATIO-SUM-AVERAGES BETWEEN INTERVAL \\
\hline 59 & c & & AND MONTH, LB H2O VAPOR PER LB ORY AIR. \\
\hline 60 & c & RANKO: & INTERVAL RANK ACCORDING TO DRY BULB TEMPERATURE. \\
\hline 61 & c & SCALEO: & NDRMALIZED RANK ACCORDING TO DRY BULB TEMPERATURE. \\
\hline 62 & c & SCALE 1: & NORMALI ZED RANK ACCORDING TO FORMULA. \\
\hline 63 & c & SCALE2: & NORMALIZEO RANK ACCORDING TO TOTAL TEMPERATURE RANGE. \\
\hline 64 & c & INTVAL: & CRDER OF INTERVALS IN MONTH FROM SUBROUTINE ORDER. \\
\hline 65 & c & I0: & ORDER OF INTERVALS IN MONTH FOR DRY BULB TEMPERATURE. \\
\hline 66 & c & I 1: & GRDER OF INTERVALS IN MONTH ACCORDING TO FORMULA. \\
\hline 67 & c & I2: & ORDER OF INTERVALS IN MONTH ACCORDING TO TOTAL RANGE. \\
\hline 68 & c & OB2AVM: & INPUT DRY BULB AVERAGE FOR BIASING SELECTION FROM LONG- \\
\hline 69 & C & & TERM MONTHLY AVERAGES, F。 \\
\hline 70 & c & DP2AVM: & INPUT DEWPOINT AVERAGE FOR BIASING SELECTION FROM LONG- \\
\hline 71 & c & & TERM MONTHLY AVERAGES。 F。 \\
\hline 72 & c & CCAD2M: & INPUT SUNLIT CLOUD COVER AVERAGE FOR BIASING SELECTION FROM \\
\hline 73 & c & & LONG-TERM MONTHLY AVERAGES. TENTHS. \\
\hline 74 & c & WSAVM: & INPUT WINDSPEED AVERAGE FOR BIASING SELECTION FROM LONG- \\
\hline 75 & c & & TERM MONTHLY AVERAGES, MPH. \\
\hline 76 & C & PBT2M: & INPUT BAROMETRIC PRESSURE AVERAGE FOR BIASING SELECTION \\
\hline 77 & c & & FROM LONG-TERM MONTHLY AVERAGES, IN. HG. \\
\hline 78 & c & ISELCT: & BEST INTERVAL FOR MONTH. \\
\hline 79 & c & WA2M: & CALCULATED MOISTURE-RATIO-SUM FOR BIASING SELECTION FROM \\
\hline 80 & c & & MONTHLY AVERAGES, LB HZO VAPOR PER LB DRY AIR• \\
\hline 81 & c & DRSPAN: & AVERAGE DAILY RANGE FOF INTERVAL, F. \\
\hline 82 & c & NUMDAY: & NUMBER OF DAYS IN YEAR. \\
\hline 83 & c & IINT: & LENGTH OF INTERVAL IN DAYS. \\
\hline 84 & c & MONTH: & NUMBER OF MONTH. \\
\hline 85 & C & IDAY: & DAY OF MONTH. \\
\hline 86 & c & AVG: & DRY BULB TEMPERATURE AVERAGE, $F$ • \\
\hline 87 & c & DAYMAX: & DAILY MAXIMUM TEMPERATURE, F。 \\
\hline 88 & C & DAYMIN: & DAILY MINIMUM TEMPERATURE\& F。 \\
\hline 89 & c & CC: & $\begin{array}{l}\text { CLOUD COVER, TENTHS. } \\
\text { SUNLIT CLOUD CLOUD COVER, TENTHS. }\end{array}$ \\
\hline $\begin{array}{l}90 \\
91\end{array}$ & $\begin{array}{l}c \\
c\end{array}$ & $\begin{array}{l}\text { CCAD: } \\
\text { WA: }\end{array}$ & $\begin{array}{l}\text { SUNLIT CLOUD CLOUD COVER, TENTHS. } \\
\text { MOISTURE-RATIO-SUM. LB HZO PER LB DRY AIR. }\end{array}$ \\
\hline 92 & c & WSDB: & WINDSPEED DPY-BULB-TEMPERATURE-PRODUCT, F $X \mathrm{MPH}$. \\
\hline 93 & c & ILONG: & SWITCH FOR AVERAGE CHANGING MODE. \\
\hline 94 & c & CLAVGM: & AVERAGE CLOUDINESS FOR MONTH, TENTHS. \\
\hline 95 & c & DBAVGM: & AVERAGE DRY BULB TEMPERATURE FOR MONTH, F. \\
\hline 96 & C & DRAVGM: & AVERAGE DAILY RANGE FOR MONTH, $F$. \\
\hline 97 & c & CCADM: & AVERAGE SUNLIT CLOUD COVER FOR MONTH, TENTHS. \\
\hline 98 & c & WSDBM: & AVERAGE WIND-SPEED-TEMPERATURE-PRODUCT FOR MONTH, $F \times$ MPH. \\
\hline 99 & c & WAM: & AVERAGE MOISTURE-RATIO-SUM FOR MONTH, LB H2O VAPOR PER LB \\
\hline 100 & c & & DRY AIR。 \\
\hline 102 & c & A2ED: & SAVING VARIABLE FOR DBAVGM. \\
\hline 102 & c & A3ED: & SAVING VARI ABLE FOR CCADM. \\
\hline 103 & c & A4ED: & SAVING VARIABLE FOR WSOBM. \\
\hline 104 & c & A5ED: & SAVING VARIABLE FOR WAM. \\
\hline 105 & c & NSPAN: & NUMBER OF INTERVALS IN MONTH. \\
\hline 106 & c & DBX: & SUMMING VARIABLE FOR INTERVAL DRY BULB TEMPERATURE. \\
\hline 107 & c & DRX: • & SUMMING VARIABLE FOR INTERVAL DAILY RANGE. \\
\hline 108 & c & CCX: & SUMMING VARIABLE FOR INTERVAL CLOUD COVER. \\
\hline 109 & c & CCADX: & SUMMING VARIABLE FOR INTERVAL SUNLIT CLOUD COVER. \\
\hline 130 & C & WSDBX: & SUMMING VARIABLE FOR INTERVAL WIND-SPEED-TEMPERATURE-PF \\
\hline 111 & c & WAX: & SUMIIING VARIABLE FOR INTERVAL MOISTURE-RATIO-SUM. \\
\hline 182 & c & SPMAX: & INTERVAL MAXIMUM TEMPERATURE. \\
\hline 113 & c & SPMIN: & INTERVAL MINIMUM TEMPERATURE• \\
\hline 114 & c & FACTOS: & NORMALIZING VARIABLE FOR TEMPERATURE SC \\
\hline 115 & C & FACTOR: & NORMALIZING VARIABLE FOR FCRMU \\
\hline
\end{tabular}




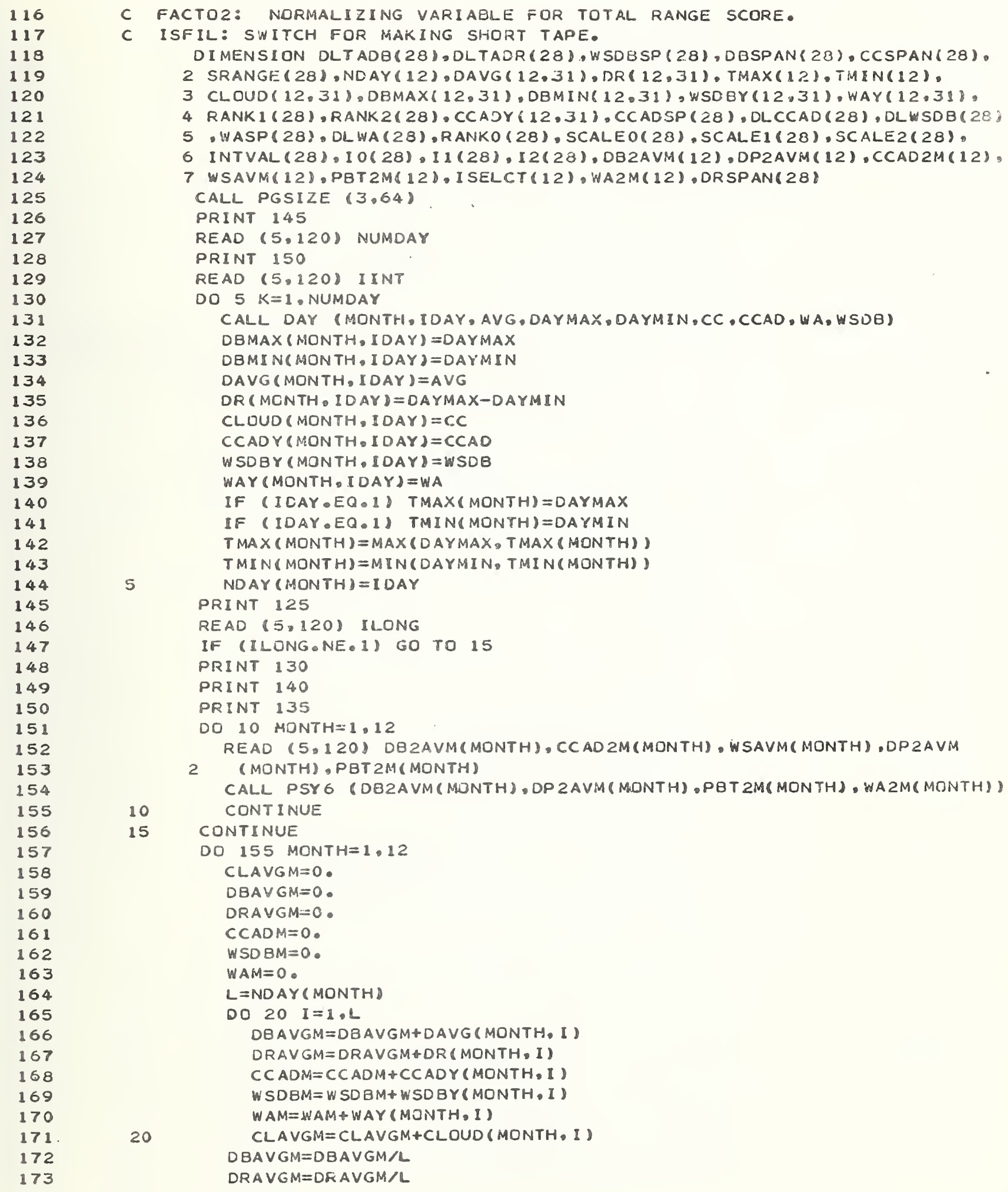

C FACTO2: NORMALIZING VARIABLE FOR TOTAL RANGE SCORE.

C ISFIL: SWITCH FOR MAKING SHORT TAPE.

DIMENSION DLTADB(28), DLTADR (28),WSDBSP (28), DBSPAN(28), CCSPAN(28).

2 SRANGE (28), NDAY (12), DAVG (12,31), DR (12,31), TMAX(12), TMIN(12),

3 CLOUO $(12,31), \operatorname{DBMAX}(12,31)$, DBMIN 12.31$),$ WSDBY $(12,31), W A Y(12.31)$,

4 RANK $1(28), \operatorname{RANK} 2(28), \operatorname{CCADY}(12,31), \operatorname{CCADSP}(28), \mathrm{DLCCAD}(28), \mathrm{DLWSB}(28)$

5. WASP (28), DLWA (28), RANKO (28), SCALEO(28), SCALE1 (28), SCALE2 (28),

6 INTVAL (28), IO(28), I $1(28), I 2(28)$, DB2AVM (12), DP2AVM(12),CCAD2M(12),

7 WSAVM(12), PBT2M(12), ISELCT(12), WA2M(12),DRSPAN( 28 )

CALL PGSIZE $(3,64)$

PRINT 145

READ $(5,120)$ NUMDAY

PRINT 150

READ (5,120) IINT

DO $5 K=1$. NUMDAY

CALL DAY (MONTH, IDAY, AVG, DAYMAX, DAYMIN,CC, CCAD, WA,WSDB)

DBMAX (MONTH, IDAY) =DAYMAX

DBMIN(MONTH, IDAY) = DAYMIN

DAVG (MONTH,IDAY) =AVG

DR (MCNTH. IOAY I=DAYMAX-DAYMIN

CLOUD ( $M O N T H, I D A Y)=C C$

CCADY $(M O N T H, I D A Y)=C C A D$

WSDBY (MONTH, IDAY) =WSDB

WAY (MONTH, IDAY) =WA

IF (ICAY EQ.1) TMAX(MONTH) =DAYMAX

IF (IDAY,EQ.1) TMIN(MONTH) =DAYMIN

$T M A X(M O N T H)=M A X(D A Y M A X, T M A X(M O N T H))$

TMIN $(M O N T H)=M I N(D A Y M I N, T M I N(M O N T H))$

NDAY (MONTH) = IDAY

PRINT 125

READ $(5,120)$ ILONG

IF (ILONG.NE.1) GO TO 15

PRINT 130

PRINT 140

PRINT 135

DO 10 MONTH $=1,12$

READ (5.120) DBZAVM(MONTH), CCAD2M(MONTH), WSAVM(MONTH),DP2AVM (MONTH),PBT2M(MONTH)

CALL PSY 6 (DBZAVM(MONTH), DP 2AVM(MONTH),PBT2M(MONTH), WA2M(MONTH)) CONTINUE

CONTINUE

DO 155 MONTH=1.12

CLAVGM $=0$.

$D B A \forall G M=0$.

DRA YGM $=0$.

$C C A D M=0$.

$W S O B M=0$.

$W A M=0$.

L=NOAY (MONTH)

DO $20 \quad I=1, L$

DBAVGM=DBAVGM+DAVG (MONTH, I)

DRAVGM=DRAVGM+DR (MONTH, I)

$C C A D M=C C A D M+C C A D Y$ (MONTH, I)

$W S D B M=W S D B M+W S D B Y(M O N T H, I)$

$W A M=W A M+W A Y$ (MONTH, I)

CLAVGM =CLAVGM+CLOUD (MONTH, I)

$D B A \vee G M=D B A \vee G M / L$

$D R A V G M=D F A V G M / L$ 


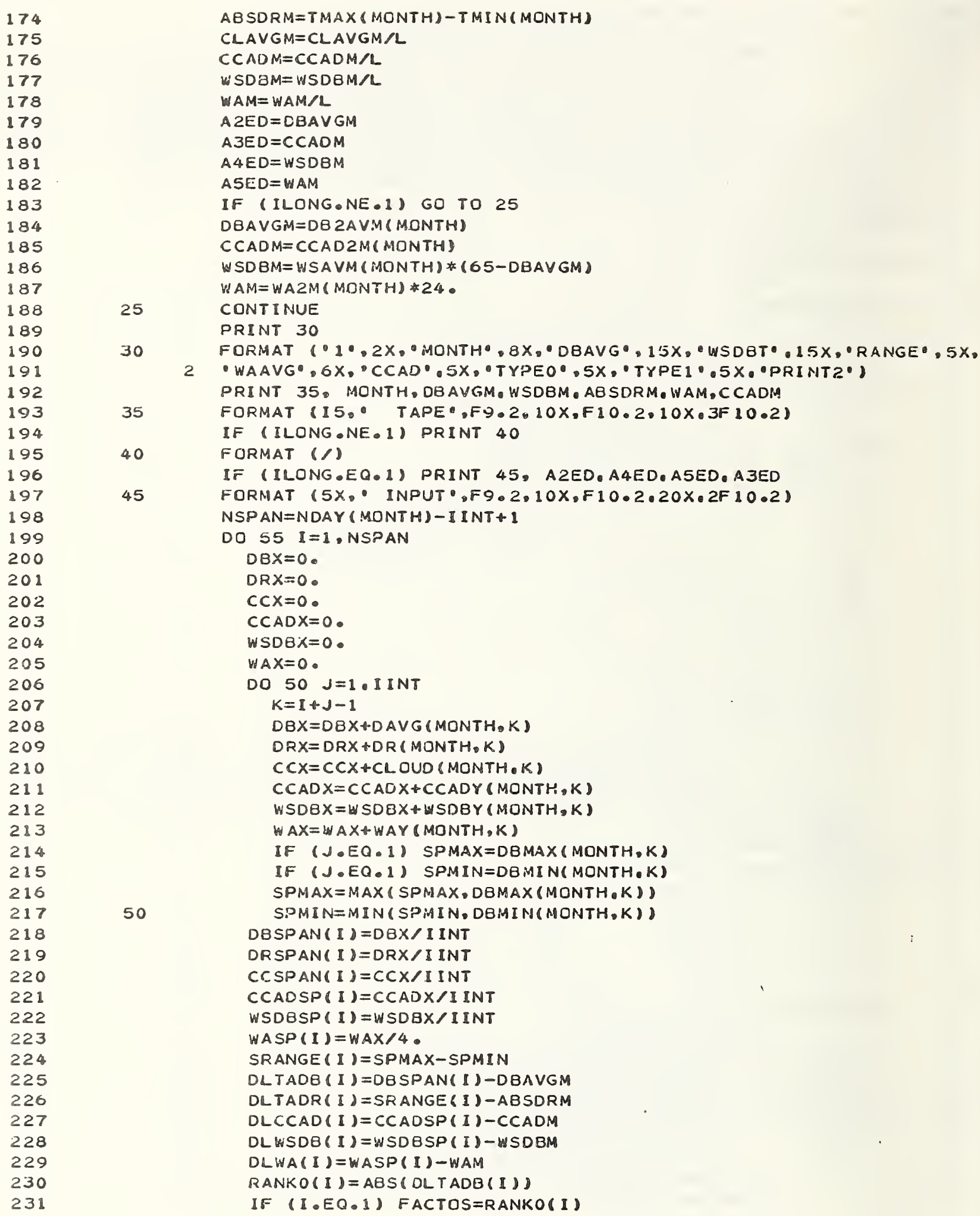

ABSDRM $=$ TMAX $(M O N T H)-T M I N(M O N T H)$

CLAVGM $=$ CLAVGM/L

$C C A D M=C C A D M / L$

WSDBM $=$ WSDBM/L

$W A M=W A M / L$

$A 2 E D=D B A V G M$

$A 3 E D=C C A D M$

$A 4 E D=W S D B M$

$A 5 E D=W A M$

IF (ILONG.NE.1) GO TO 25

DBAVGM=DB 2AVM (MONTH)

CCADM $=$ CCAD2M(MONTH)

WSDBM = WSAVM (MONTH) * (65-DBAVGM)

WAM $=W A 2 M(M D N T H) * 24$.

25

30

35

40

45

CONTINUE

PRINT 30

FORMAT $1^{\circ} 1^{\circ}, 2 X,{ }^{\circ} M O N T H * .8 X, 0^{\circ}$ DBAVG $, 15 X,{ }^{\circ}$ WSDBT $, 15 X,{ }^{\circ}$ RANGE, $5 X$,

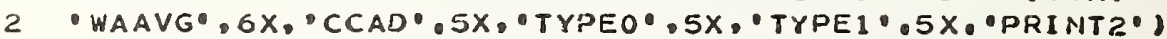

PRINT 35, MONTH, DBAVGM, WSDBM, ABSDRM. WAM,CCADM

FORMAT (I5." TAPE ,FY.2.10X,F10.2.10X.3F 10.2)

IF (ILONG $\odot$ NE.1) PRINT 40

FORMAT (/)

IF (ILONG.EQ.1) PRINT 45, A2ED. A4ED.A5ED. A3ED

FORMAT (5X," INPUT "F9.2.10X,F10.2.20X.2F 10.2)

NSPAN=NDAY $($ MONTH $)-\mathbb{I} I N T+1$

DO $55 I=1, N S P A N$

$D B X=0$.

$D R X=0$.

$C C X=0$.

$C C A D X=0$.

$W S D B X=0$

$W A X=0$.

DO $50 \mathrm{~J}=1$. IINT

$K=I+J-1$

$D B X=D B X+D A V G(M O N T H, K)$

$D R X=D R X+D R(M O N T H, K)$

$C C X=C C X+C L$ OUD (MONTH.K)

$C C A D X=C C A D X+C C A D Y(M O N T H, K)$

$W S D B X=W S D B X+W S D B Y(M O N T H, K)$

$W A X=W A X+W A Y(M O N T H, K)$

IF $(J \cdot E Q .1)$ SPMAX $=D B M A X(M O N T H, K)$

IF (J.EQ.1) SPMIN=DBMIN(MONTH.K)

SPMAX $=$ MAX (SPMAX,DBMAX (MONTH,K))

SPMIN $=M I N(S P M I N, D B H I N(M O N T H, K))$

DBSPAN (I) $=D B X /$ I INT

DRSPAN (I) = DRX /IINT

CESPAN(I) $=C C X / I I N T$

CCADSP (I) $=C C A D X / I I N T$

WSDBSP $(I)=W S D B X / I I N T$

$W A S P(I)=W A X / 4$.

SRANGE $(I)=$ SPMAX-SPMIN

$D L T A O B(I)=D B S P A N($ I) $-D B A V G M$

DLTADR (I) =SRANGE (I)-ABSDRM

DLCCAD $(I)=C C A D S P(I)-C C A D M$

DLWSDB (I) =WSDBSP (I) - WSDBM

$\operatorname{DLWA}(I)=$ WASP (I) - WAM

RANKO(I) $=A B S(D L T A D B(I))$

IF (I.EQ.1) FACTOS=RANKO (I) 
FACTOS=MAX(FACTOS, RANKO (I))

RANK! (I) $=7.53 * A B S(D L T A D B(I))+4.64 * A B S($ DLCCAD (I)) +. I*ABS (DLWSDB (I) $1+4.5 * 1.06 * 80$ * ABS (DLWA(I))

IF (I.EQ.1) FACTOR=RANKI (I)

$F A C T O R=M A X(F A C T O R, R A N K 1(I))$

RANK2 (I) = ABS(DLTADR (I))

IF (I.EQ.1) FACTO2=RANK2(I)

FACTO2=MAX (FACTC2, RANK2 (I)) CONTINUE

PRINT 60

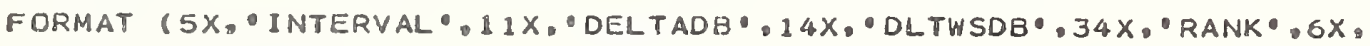




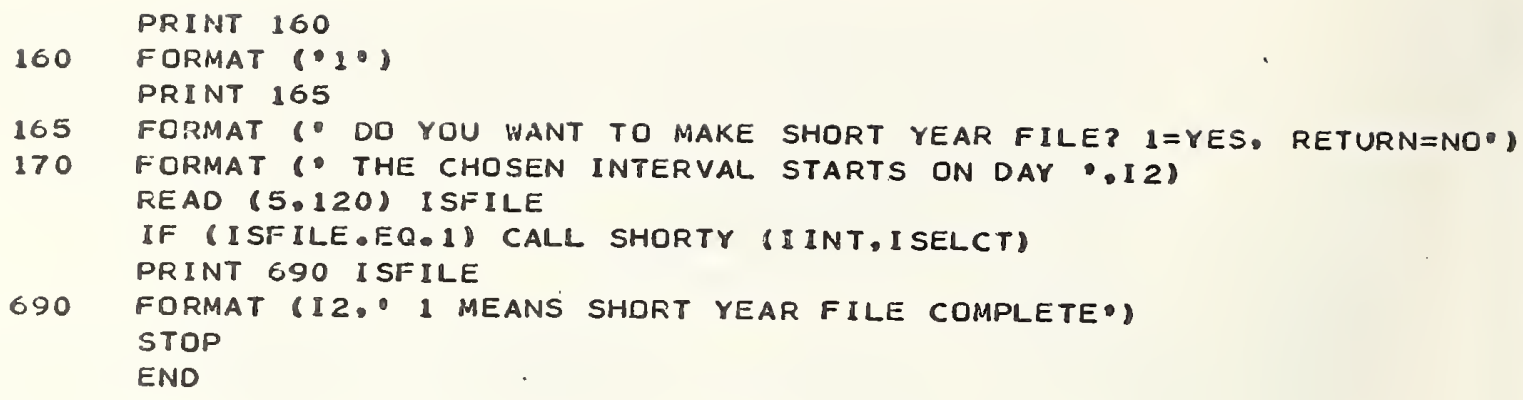




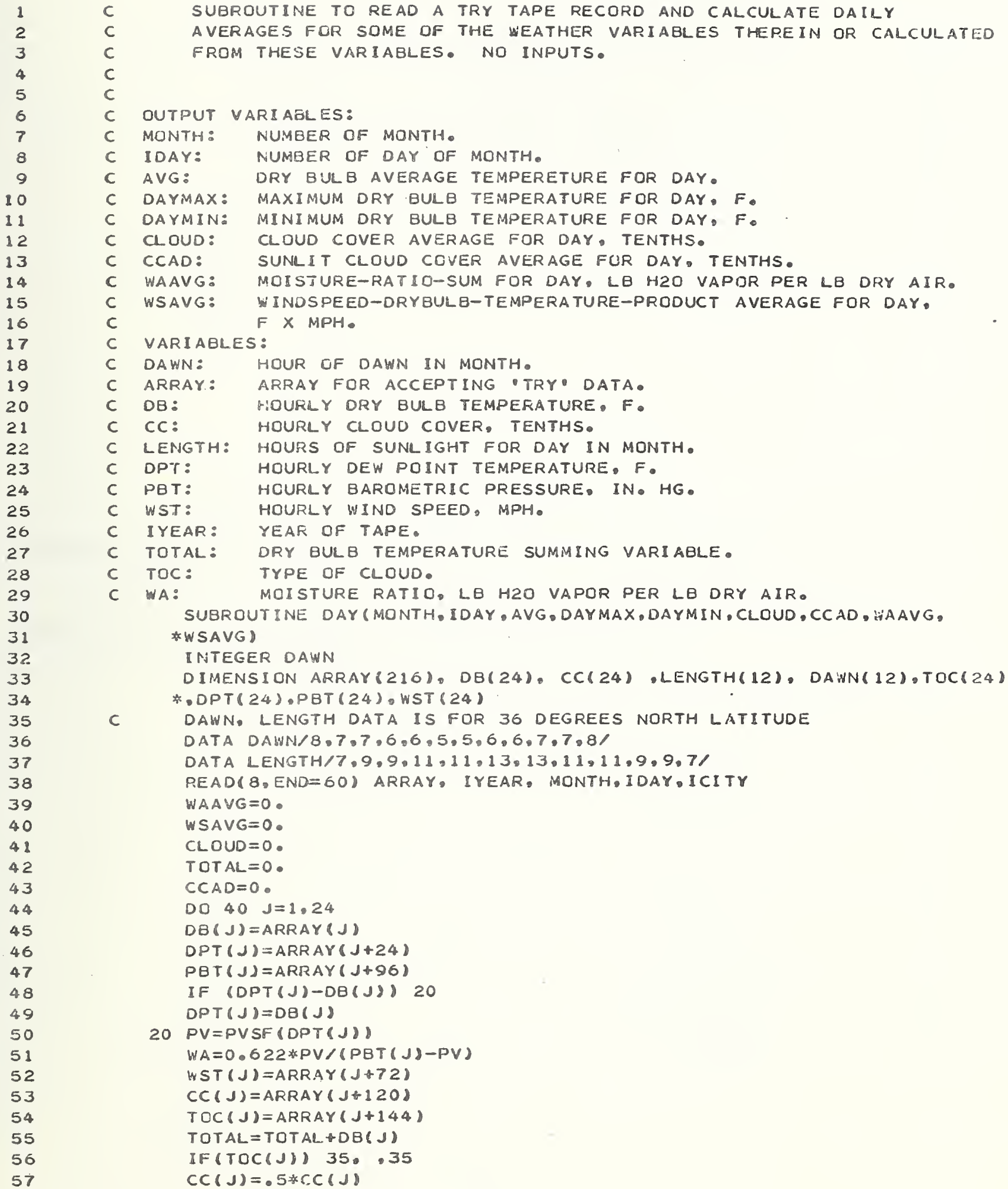


$35 C L O U D=C L O U D+C C(J)$

$W A A V G=W A A V G+W A$

WSAVG $=W S A V G+W S T(J) *(65-D B(J))$

IF (J.EQ.1) DAYMAX $=D B(J)$

$I F(\lambda, E G \bullet 1)$ DAYMIN $=D B(\lambda)$

DAYMAX $=$ MAX (DAYMAX,DB(J))

40 DAYMIN=MIN(DAYMIN,DB(S))

CL OUD $=$ CLOUD/24.

AVG $=$ TOTAL/24.

$W S A V G=W S A V G / 24$

I $1=$ DAWN (MONTH)

$I 2=I 1+L E N G T H(M O N T H)$

DD $50 \quad I=I 1 . I 2$

$50 C C A D=C C A D+C C$ (I)

$C C A D=C C A D /(L E N G T H(M O N T H)+1)$

RETURN

60 RETURN

END

SUBROUTINE ORDER(TEMP,V,N)

C

C INPUTS:

C TEMP:

C. $\%:$

C

C N:

A SLORE TO BE ORDERED.

ARRAY CONTAINING ORDINAL POSITION (IN INCREASING ORDER) OF ELEMENTS IN TEMP.

C OUTPUTS:

C TEMP:

NUMBER OF ELEMENTS TO BE ORDERED.

$c$

DIMENSICN TEMP(1),V(1),AA(200),AB(200)

DO $50 \quad I=1 . N$

$B A=1499$.

DO $25 \lambda=1, N$

IF (BA-TEMP(J) 25.25 ,

$\mathrm{K}=\mathrm{J}$

$B A=T E M P(\$)$

25 CONTINUE

$\operatorname{TEMP}(K)=1500$.

$A A(I)=B A$

$50 \quad A B(I)=V(K)$

DO $75 L=1, N$

$\operatorname{TEMP}(L)=A A(L)$

$75 V(L)=A B(L)$

RETURN

END 


\section{FEDERAL INFORMATION PROCESSING STANDARD SOFTWARE SUMMARY}

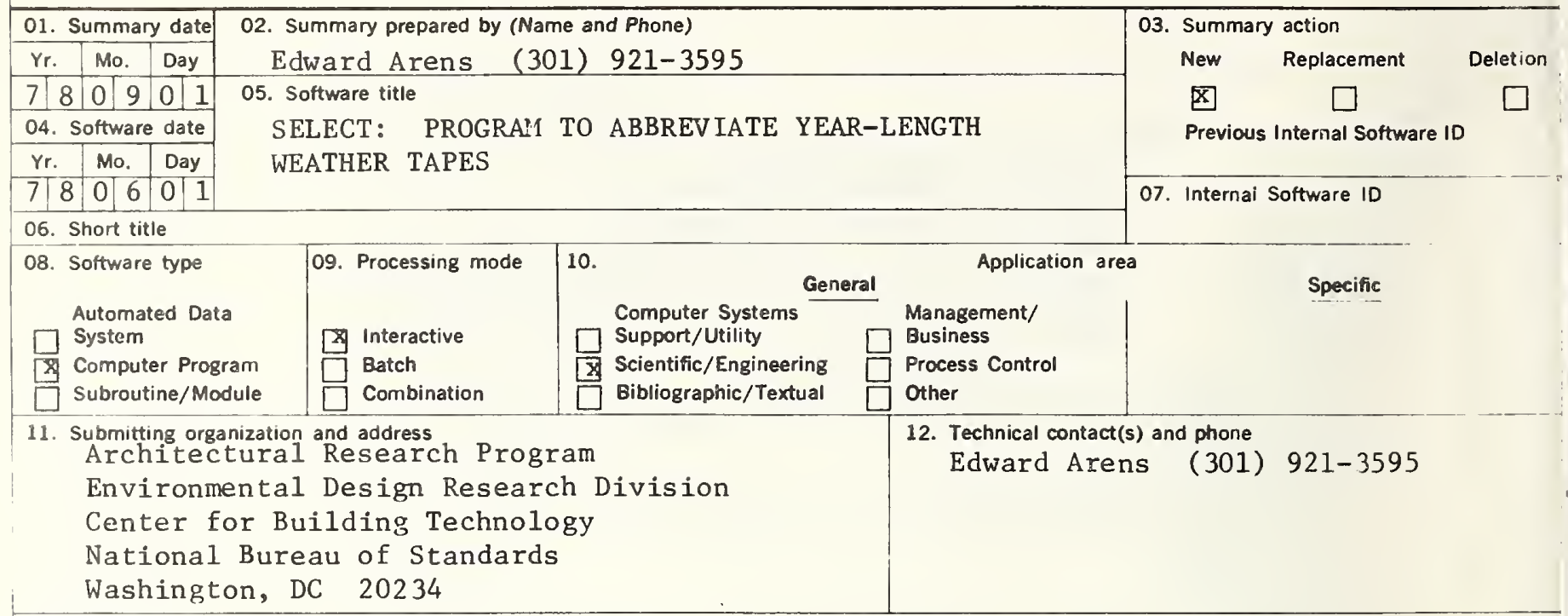

\section{Narrative}

Interactive program, plus five subroutines, abbreviates year-length weather tapes in the format required for NBSLD by selecting short contiguous intervals of days to represent each month. The selection algorithm was derived from regression of climate variables against simulated loads of a variety of envelope-dominated buildings.

\section{Keywords}

Energy; climate data; buildings.

\begin{tabular}{|l|l|l|c|}
\hline $\begin{array}{l}\text { 15. Computer manuf'r and model } \\
\text { UNIVAC } 1108\end{array}$ & 16. Computer operating system & $\begin{array}{c}\text { 17. Programing language(s) } \\
\text { FORTRAN V }\end{array}$ & $\begin{array}{c}\text { 18. Number of source program state } \\
\text { ments } \\
486\end{array}$ \\
\hline $\begin{array}{l}\text { 19. Computer memory requirements } \\
\text { IOOK }\end{array}$ & $\begin{array}{c}\text { 20. Tape drives } \\
\text { None }\end{array}$ & $\begin{array}{c}\text { 21. Disk/Drum units } \\
\text { L + S tracks, input/ } \\
\text { output }\end{array}$ & $\begin{array}{c}\text { 22. Terminals } \\
132 \text { character/ } \\
\text { line }\end{array}$ \\
\hline
\end{tabular}

\section{Other operational requirements}

\begin{tabular}{|c|c|c|c|c|c|}
\hline 24. Software & & & 25. Document & & \\
\hline $\begin{array}{l}\text { Available } \\
\text { [X] }\end{array}$ & $\begin{array}{c}\text { Limited } \\
\square\end{array}$ & $\begin{array}{c}\text { In-house only } \\
\square\end{array}$ & $\begin{array}{c}\text { Available } \\
\text { X }\end{array}$ & $\begin{array}{c}\text { Inadequate } \\
\square\end{array}$ & $\begin{array}{c}\text { In-house only } \\
\square\end{array}$ \\
\hline
\end{tabular}


NBS.114A (REV. 11.77 )

\begin{tabular}{|c|c|c|c|}
\hline $\begin{array}{l}\text { U.S. DEPT. OF COMM. } \\
\text { BIBLIOGRAPHIC DATA } \\
\text { SHEET }\end{array}$ & $\begin{array}{l}\text { 1. PUBLICATION OR REPORT NO. } \\
\text { NBSIR } 78-1525\end{array}$ & $\begin{array}{l}\text { 2. Gov't Accession } \\
\text { No. }\end{array}$ & 3. Recipient's Accession No. \\
\hline \multirow{2}{*}{\multicolumn{3}{|c|}{$\begin{array}{l}\text { 4. TITLE AND SUBTITLE } \\
\text { Climate Data Abbreviation for the Computerized Calculation of } \\
\text { Heating and Cooling Requirements in Buildings }\end{array}$}} & $\begin{array}{l}\text { 5. Publication Date } \\
\text { December } 1978\end{array}$ \\
\hline & & & 6. Performing Organization Code \\
\hline $\begin{array}{l}\text { 7. AUTHOR(S) } \\
\text { Edward A. Arens a }\end{array}$ & Daniel H. Na11 & & 8. Performing Organ. Report No. \\
\hline \multicolumn{3}{|c|}{ 9. PERF OR MING ORGANIZATION NAME AND ADDRESS } & 10. Project/Task/Work Unit No. \\
\hline \multicolumn{3}{|c|}{$\begin{array}{l}\text { NATIONAL BUREAU OF STANDARDS } \\
\text { DEPARTMENT OF COMMERCE } \\
\text { WASHINGTON, D.C. } 20234\end{array}$} & 11. Contract/Grant No. \\
\hline \multirow{2}{*}{\multicolumn{3}{|c|}{ 12. Sponsoring Organization Name and Complete Address (Street, City, State, ZIP) }} & $\begin{array}{l}\text { 13. Type of Report \& Period } \\
\text { Covered }\end{array}$ \\
\hline & & & 14. Sponsoring Agency Code \\
\hline
\end{tabular}

15. SUPPLEMENTARY NOTES

16. ABSTRACT (A 200-word or less factual summary of most significant information. If document includes a significant bibliography or literature survey, mention it here.)

This paper documents the development of a climate data abbreviation technique for building thermal analysis. The paper first discusses the characteristics of camputerized building thermal simulations and the requirements for abbreviated data. The technique is then described together with the statistical analyses used to develop it. A series of tests of the representativeness of the abbreviated climate data are documented. Finally, the limitations and potentials of the abbreviation technique are discussed.

17. KEY WORDS (six to twelve entries; alphabetical order; capitalize only the first letter of the first key word unless a proper name; separated by semicolons)

Climate data; computer; energy; lcad-calculation; residential; weather

18. AVAILABILITY

$\square$ For Official Distribution. Do Not Release to NTIS

$\square$ Order From Sup. of Doc., U.S. Government Printing Office Washington, D.C. 20402, SD Stock No. SN003-003

$\square$ Order From National Technical Information Service (NTIS) Springfield, Virginia 22151

\begin{tabular}{|l|c|}
$\begin{array}{l}\text { 19. SECURITY CLASS } \\
\text { (THIS REPURT) }\end{array}$ & 21. NO. OF PAGES \\
UNCL ASSIFIED & 66 \\
\hline $\begin{array}{l}\text { 20. SECURITY CIASS } \\
\text { (THIS PAGE) }\end{array}$ & 22. Price \\
UNCLASSIFIED & $\$ 5.25$ \\
\hline
\end{tabular}


- $\quad i$

i.

, 